University of Rhode Island

DigitalCommons@URI

Open Access Master's Theses

1997

\title{
A Comparison of Continuous Performance Tasks Using Cognitive Versus Sensory Stimuli
}

Nancy J. Reeve

University of Rhode Island

Follow this and additional works at: https://digitalcommons.uri.edu/theses

\section{Recommended Citation}

Reeve, Nancy J., "A Comparison of Continuous Performance Tasks Using Cognitive Versus Sensory Stimuli" (1997). Open Access Master's Theses. Paper 1601.

https://digitalcommons.uri.edu/theses/1601

This Thesis is brought to you for free and open access by DigitalCommons@URI. It has been accepted for inclusion in Open Access Master's Theses by an authorized administrator of DigitalCommons@URI. For more information, please contact digitalcommons-group@uri.edu. 


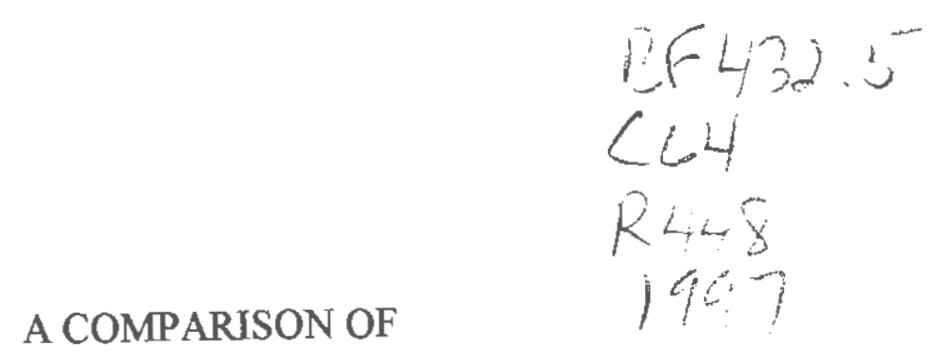
CONTINUOUS PERFORMANCE TASKS

USING COGNITIVE VERSUS SENSORY STIMULI

BY

NANCY J. REEVE

A THESIS SUBMITTED IN PARTIAL FULFILLMENT OF THE REQUTREMENTS FOR THE DEGREE OF

MASTER OF ARTS

IN

PSYCHOLOGY

$3 \div 36-1$

University of Rhode Island 


\begin{abstract}
A comparison of continuous performance tasks (CPTs) using cognitive versus sensory stimuli was undertaken to compare vigilance performance on analogous verbal and non-verbal tasks in normal, young adults. Eighty-nine introductory psychology students, screened for head injury, neurological deficits, and medication and substance use performed two versions of an auditory, computerized CPT. In the verbal task, stimuli were letters of the alphabet, whereas in the non-verbal task, they were tones of the major diatonic scale. During each $15 \mathrm{~min}$ task, 1200 stimuli were presented at an onset-to-onset time of $0.75 \mathrm{sec}$. A total of 100 targets was presented in semi-random sequence at an average rate of one every $9 \mathrm{sec}$. Targets were constituted by stimuli that were identical to the immediately preceding stimulus. Participants were required to respond to targets with the press of a hand-held button.
\end{abstract}

Results indicated significant differences between the two versions of the task on accuracy, adjusted accuracy, and false alarm rate. In addition, correlations were found both within and between the tasks for accuracy, adjusted accuracy, and reaction time. Implications of these results for models of attention, theories of laterality and attentional mechanisms, and clinical use are discussed. 


\section{TABLE OF CONTENTS}

List of Tables

List of Figures

vi

Introduction

1

Method

12

Results

18

Discussion

26

References

Appendix

Bibliography

60 


\section{LIST OF TABLES}

Table 1 Means and Standard Deviations for Accuracy on the Letter and Tone Tasks by Block and Presentation Order

Table 2 Means and Standard Deviations for Adjusted Accuracy on the Letter and Tone Tasks by Block and Presentation Order

Table 3 Means and Standard Deviations for the Error Index on the Letter and Tone Tasks by Block and Presentation Order

Table 4 Means and Standard Deviations for Reaction Time on the Letter and Tone Tasks by Block and Presentation Order

Table $5 \quad$ Means and Standard Deviations for Number of False Alarms on the Letter and Tone Tasks by Block and Presentation Order

Table 6 Correlations for Accuracy by Block between the Letter and Tone Tasks

Table 7 Correlations for Adjusted Accuracy by Block between the Letter and Tone Tasks 
Table 8 Correlations for Reaction Time by Block between the Letter and Tone Tasks

Table 9 Correlation for Error Index by Block between the Letter and Tone Tasks

Table 10 Correlations for False Alarms by Block between the Letter and Tone Tasks

Table 11 Correlations within the Letter Task

Table 12 Correlations within the Tone Task

Table 13 Correlations for Total Performance Measures Collapsed over Task 


\section{LIST OF FIGURES}

Figure 1 Mean accuracy by block for the letter and tone tasks.

Figure 2 Mean accuracy by order by block for the letter and tone tasks.

Figure 3 Mean accuracy by block for task when the task comes first or second in the presentation order.

Figure 4 Mean adjusted accuracy by block for the letter and tone tasks.

Figure 5 Mean adjusted accuracy by order by block for the letter and tone tasks.

Figure 6 Mean adjusted accuracy by block for task when the task comes first or second in the presentation order.

Figure 7 Mean reaction time by block for the letter and tone tasks.

Figure 8 Mean reaction time by order by block for the letter and tone tasks.

Figure 9 Mean reaction time by block for task when the task comes first or second in the presentation order. 
Figure 10 Mean number of false alarms by block for the letter and tone tasks.

Figure 11 Mean number of false alarms by order by block for the letter and tone tasks.

Figure 12 Mean number of false alarms by block for task when the task comes first or second in the presentation order. 


\section{Introduction}

Sustained attention, or vigilance, is the ability to focus on a single task for an extended period of time. The capacity to sustain attention is fundamental to behavioral adaptation, playing important roles in the detection of external dangers and necessary natural resources, and in intraspecies communication (Warm, 1984). In terms of human behavior, it is also a primary aspect of perceptual functioning (Warm, 1984).

Sustained attention is believed to be only one of several components of the broader concept of attention. According to a cognitive model of attention by Prather and Kaplan (in press), sustained attention is a component of a generalized, but complex, construct of attention that subsumes several interrelated processes. Moderating variables include arousal and rate of processing, whereas specific functional aspects include orienting, maintenance of attention (i.e. sustained attention), selective attention, expectancy, and integration (Prather \& Kaplan, in press). According to this model, it is likely then that any measure of sustained attention would be moderated by arousal and rate of processing, and affected by the other specific aspects of attention.

In most cases, vigilance declines as a function of time spent on task (Tomporowski \& Tinsley, 1994). Vigilance decrements are probably the most ubiquitous finding in research on sustained attention (Warm, 1984). It has been shown that half of the vigilance decrement occurs in the first 15 min of a task, and that the decrement is complete within 25 to 30 min (Tiechner, as cited in Warm, 1984). Parasuraman (1984) has argued that on tasks with successively presented stimuli and short onset-to-onset times (less than $1.0 \mathrm{sec}$ ) 
the vigilance decrement occurs earlier. Jerison (as cited in Warm, 1984) has noted a decline in vigilance from the first signal onward.

Vigilance tasks, according to Warm (1977, as cited in Warm, 1984), are comprised of several specific features: (a) the task is prolonged and continuous; (b) the signals are clearly discernible once alerted to them; (c) targets occur infrequently, aperiodically, and without forewarning; and (d) the subjects' response does not alter the likelihood of target presentation.

According to Parasuraman (1984), there are three facets of vigilance performance: (a) the overall level of performance, which is influenced by arousal, (b) vigilance decrements resulting from changes in expectancy, subjective probability, and response criteria, and (c) vigilance decrements due to decreased perceptual sensitivity in tasks with both high event rates and memory load (i.e., successive tasks). It is therefore important to distinguish between vigilance decrement (a reduction in performance with time spent on task) and overall level of performance. Arousal, the physiological and behavioral states characterized by increased energy and excitation, is only related to overall level of performance and is assumed to be constant during the course of the test.

Pribram and McGuiness (as cited in Parasuraman, 1984) have identified three interacting neural systems that control arousal, activation (i.e., expectancy), and effort (the attentional process necessary to coordinate arousal and activation). Tonic arousal is related to neural circuitry in the amygdala and frontal cortex. Phasic activation is a function of the basal ganglia, whereas effort is related to the hippocampus. 
Parasuraman (1984) suggests that the neural circuits identified by Pribram and McGuiness (as cited in Parasuraman, 1984) may be associated with the three facets of vigilance performance, with arousal being related to overall level of performance, activation to decrements in expectancy-related criteria, and effort to sensitivity decrements.

Laterality

Decades of research, pioneered by Wernicke and Broca, and, more recently, Luria, have demonstrated the left hemisphere's dominant role in the processing of linguistic stimuli and the right hemisphere's role in prosody and spatial stimuli. In addition, Luria (1973) has reported differences in speech and music hearing. Speech hearing may be impaired by damage to the left temporal lobe, whereas music hearing is spared. The reverse can also occur in damage to the right temporal lobe, with speech hearing remaining intact and music hearing showing deficits.

Neural theories of attention (Posner, 1992; Whitehead, 1991) suggest that the right hemisphere plays an important role in performance on vigilance tasks. However, vigilance deficits have been seen with damage to either hemisphere of the brain (Davies \& Parasuraman, 1982; Parasuraman, 1984). Although some studies have reported a right hemisphere superiority in split-brain patients, results obtained with normal participants are not comparable, leading to the view that the functional organization of the hemispheres in split-brain patients is fundamentally different from that of intact individuals (Davies \& Parasuraman, 1982). Therefore, Davies and Parasuraman (1982) suggest that although the right hemisphere exhibits superiority in vigilance tasks in split-brain patients, possibly due 
to either the left hemisphere's inability to exert inhibitory effects or actual differences in sensitivity between the hemispheres, for normals, differences between the hemispheres on vigilance tasks has yet to be reliably demonstrated. Warm et al. (1980, as cited in Warm, 1984) suggest that the right hemisphere may dominate in sustaining attention over time, whereas overall performance may depend on the integration of the two hemispheres.

This is in contrast with a study by Podell, Lovell, Zimmerman, and Goldberg (1995) who propose "a dynamic balance between two synergistic decision-making systems in the frontal lobes: context-dependent in the left hemisphere and context-invariant in the right". The left hemisphere is critical for processing involving preexisting representations and routinized cognitive strategies and may be related to focused attention, whereas the right hemisphere is critical for processing of novel situations and may be related to global attention (Podell et al., 1995). Furthermore, they also propose neurotransmitter-related attentional biases, with norepinephrine being prevalent in the right hemisphere and dopamine in the left.

Warm et al. $(1976,1980$, as cited in Warm, 1984) have reported a right ear superiority in detection latency with low target rates ( 24 targets per hour), and left ear dominance with high target event rates (96 per hour), with no difference at intermediate ranges. In addition, reaction time to left ear signals increased with time on task, while reaction times to right ear signals remained stable. However, vigilance decrements showed no ear differences. According to Warm (1984), "our knowledge of brain systems and hemispheric specialization in sustained attention has only scratched the surface." 
Loeb and Alluisi (1984) propose a multi-mechanism view of sustained attention, as opposed to a unified general position. In light of this view, Warm (1984) suggests that the development of a multiple regression model might account for the different sources of variance in vigilance performance.

\section{Emotion and Sustained Attention}

Emotions are integral to cognition, attention, and working memory, and influence an individual's ability to sustain attention on a given task (Damasio, 1994). In addition, they are integral to the decision making that is essential in processing of successive or simultaneous stimuli. Lesions of the prefrontal lobes and anterior cingulate gyrus, especially of the right hemisphere, have been shown to be associated with deficits in attention, decision-making, and emotion (Damasio, 1994).

Deficits in attention have been implicated in a wide variety of psychopathological states, including attention deficit disorder, confusional states, traumatic head injury, neglect syndromes, and dementias of various types (Prather \& Kaplan, in press).

Therefore, accurate assessment of an individual's attentional processes is essential to appropriate diagnoses and interventions. If emotional state influences performance on measures of sustained attention, then it becomes incumbent on the diagnostic team to consider the contributions of response biases due to emotional components, such as arousal and valent mood.

Complicating matters is the notion that both arousal and sustained attention can be components of models of emotion and motivation. Higgins (as cited in Azar, 1995), in his hypothesis on motivation, suggests a dimension called regulatory focus that interacts with 
emotional valence and affects performance measures. Lang (1995) has described emotions as states of vigilant readiness with arousal and affective valence (positivity/negativity) as the strategic dimensions. According to this model, emotions can be thought of as motivationally tuned states of readiness that are the products of evolution. He further proposes two motivational systems, appetitive and aversive, which account for the relative primacy of the valence dimension. Arousal is thought to reflect variations in metabolic and neural activation of either motivational system (Lang, 1995). Cuthbert, Bradley, and Lang (as cited in Lang, 1995) have found that arousal does not have an independent, unitary effect on behavior; it increases activation, but does not determine direction (which is modulated by motivation).

According to Revelle (1992), "motivation is the vital link between knowing and doing, between thinking and action, between competence and performance." He suggests that motivational states may be categorized as the affective direction and energetic intensity of motivation. Energetic arousal is thought to be a non-directional component of motivation with individuals differing systematically in their levels of energetic arousal (Revelle, 1992). However, Watson and Tellegen (as cited in Revelle, 1992) have shown that affective direction can be subdivided into positivity and negativity, which are independent of one another. And Thayer (1989) has suggested that intensity should likewise be subdivided into energetic and tense arousal.

Thayer (1989) further states that energetic arousal is associated with approach behavior and tense arousal with avoidance behavior. Meanwhile, Revelle (1992) feels that positive affect facilitates approach behaviors, whereas negative affect facilitates avoidance 
behaviors. These response tendencies are mutually exclusive. Vigilance tasks, which relate to detection and response, are affected by changes in arousal. At the same time, increased arousal facilitates detection and storage of information and the execution of the dominant response tendency (Revelle, 1992). For short performance sampling periods, energetic components of motivation and strategic trade-offs between speed and accuracy account for individual differences in motivation and performance. For longer sampling periods, such as those in typical psychology experiments, which are measured in tens of minutes, individual differences plus demands for sustained attention take precedence (Revelle, 1992).

Lang (1995) reports that the presumed indices of emotion include (a) language, (b) physiologic changes, and (c) behavioral sequelae such as performance deficits. In research by Bradley, Cuthbert, and Lang (as cited in Lang, 1995), it was found that affective modulation is not secondary to differences in modality specific attention (e.g., visual vs. auditory), and that responses indicating attention, which are not motivationally specific, are not modulated by affect. In addition, Lang (1995) reports that affective startle modulation has been found to occur most reliably during states of vigilance when the participant is stopped but actively orienting, such as during a continuous performance task.

It is commonly assumed, when studying human performance, that individuals are alert and optimally motivated. Therefore, many research studies do not consider the effect of motivation or emotion on performance. However, Matthews et al. (1989, as cited in Revelle, 1992) report three mood dimensions that may affect performance measures: 
energetic arousal, tense arousal, and hedonic tone (positive vs. negative). Revelle (1992) suggests three ways to study the relationship of arousal to performance: (a) by varying the situational demands thought to lead to arousal, (b) by correlating psychophysiological measures to performance, and (c) by correlating self-report measures of arousal with performance. Thayer (1989) has argued that subjective estimates of energetic arousal are the most likely to be associated with performance. Matthews (1989, as cited in Revelle, 1992) and Matthews et al. (1990, as cited in Revelle, 1992) have found consistent relationships between arousal and performance on simple and complex discrimination tasks. They also report that vigilance decrements can occur rapidly, with self-reported levels of high arousal related to the ability to maintain performance levels.

In addition, Broadbent (as cited in Revelle, 1992) has found variations in performance along the personality dimensions introversion-extroversion and stabilityneuroticism. Extroversion is associated with decrements in performance over time, and neuroticism with decrements following stress. Matthews (1989, as cited in Revelle, 1992) and Matthews et al. (1990, as cited in Revelle, 1992) have found that state measures of self-reported energetic arousal interact with trait measures of introversion-extroversion to affect performance on detection tasks. Revelle (1992) reports other research that has found that performance by extroverts declines more rapidly when detecting infrequent signals and in terms of variability and speed of reaction time.

\section{Continuous Performance Tasks}

One of the most widely used measures of vigilant attention is the Continuous Performance Test (CPT) which is believed to be an objective measure of sustained 
attention independent of verbal, perceptual and other cognitive processes (Halperin, Sharma, Greenblatt, \& Schwartz, 1991). CPTs are widely used as research tools and assessment instruments in clinical neuropsychological testing.

During a CPT, participants are asked to respond to visual or auditory targets that require them to focus their attention on one task for an extended period of time, and signal with the press of a button. It is assumed that missed targets are attributable to lapses in attention (Halperin et al., 1991), yet a decline in performance is not always found (Parasuraman, 1984). However, poor performance on a CPT can be due to deficits on any of the components of attention, and is not specifically under the domain of vigilance (Prather \& Kaplan, in press).

CPTs are widely divergent in their modes of measurement and presentation. In addition to differences in sensory modality, CPTs differ in the type of discrimination required (e.g., successive or simultaneous), the rate of stimulus events per minute, the number of targets per minute, the level of cognitive processing required, the temporal regularity of targets and stimulus events, the discriminability of targets compared to nontargets, the duration of the stimuli, the length of the task, and the amount and type of training received (See, Howe, Warm, \& Dember, 1995).

Although CPTs have high face validity, they have been inconsistent in differentiating between groups, and no clinical group has been shown to perform poorly on a consistent basis on the CPT (Halperin et al., 1991). Correlations between CPT results and subjective measures used to assess attention have been weak. Halperin (1991) states that "the lack of strong and consistent relationships with teacher behavior ratings 
suggests that the CPT should not be used as a clinical indicator of ADHD." He also suggests that due to the wide variability among children with $\mathrm{ADHD}$, any single measure, especially one that relates to a specific function, is unlikely to be predictive of a disorder that encompasses a wide variety of behavioral effects.

In an interesting paradox, visual CPT formats are remarkably similar to the Nintendo that Barkley (as cited in Hallowell and Ratey, 1994) avers cannot be used to distinguish attention deficits, raising doubts about the validity of CPTs in measuring sustained attention, and strengthening Lang's theory of motivation and arousal. Because available data on the construct validity of CPTs is limited, additional research is needed before accepting this task as a valid measure of sustained attention.

Pilot studies at the University of Rhode Island have reported little correlation between auditory letter and tone tasks at an onset-to-onset time of $0.5 \mathrm{sec}$. Conversely, Kastner (1994) has found a high correlation between performance on visual letter and visual abstract forms.

In addition, further pilot studies at the University of Rhode Island have demonstrated that musicians perform significantly better than non-musicians on the auditory tone task at $0.5 \mathrm{sec}$ onset-to-onset time, but that this difference is no longer apparent at $0.9 \mathrm{sec}$. Differences in performance between musicians and non-musicians on the auditory letter task have not been demonstrated. This may be due to differences in speech hearing and music hearing (Luria, 1973). 


\section{Hypotheses and Predictions}

CPTs are among the most commonly used assessment tools in the clinical diagnosis of the attention deficits associated with various forms of pathology. However, they are widely divergent in their modes of measurement and presentation with the assumption being that they are all measuring the same thing, e.g., vigilance. Most CPTs administered in a clinical setting use only one of the two stimulus types examined in this study, assuming no differences between the two. Various studies have led one to question these assumptions based upon the following observations: (a) the questionable construct validity of CPTs, (b) the differential effects of different stimulus properties on performance, (c) the lack of correlation between visual and auditory CPTs, and (d) possible hemispheric differences.

If two versions of an auditory CPT are carefully matched on all parameters other than stimulus type, and the construct validity of the CPT as a measure of sustained attention is to be upheld, we should expect to see a high correlation between the two tasks. See et al. (1994) have suggested that CPTs with cognitive stimuli (e.g., alphanumeric tasks) do not show sensitivity decrements, whereas those with sensory stimuli (e.g., tasks involving changes in physical properties of the stimuli) do. Due to the apparent importance of the distinction between cognitive and sensory stimuli, they recommend that more research should be undertaken in this area. Furthermore, they cite the paucity of high-event-rate successive tasks that used cognitive as opposed to sensory stimuli. It is also recommended that tasks requiring comparable types of judgments be 
used to remove confounding factors. This study looks at just such a comparison, using comparable high-event-rate successive cognitive and sensory stimuli tasks.

If vigilance decrements on comparable versions of a letter and tone task are analyzed by analysis of variance procedures, it is predicted that performance on the letter version of the CPT will show significantly lower decrements than performance on the tone version of the CPT as measured by accuracy, accuracy that has been adjusted for response bias, and reaction time.

In addition, vigilance task performance on two tasks that only differ on stimulus type should be highly correlated if there is a single set of underlying mechanisms that determine performance. If criterion validity is to be upheld for these two versions of the $\mathrm{CPT}$, and they are in fact both measuring a unified construct of sustained attention, we would expect to find a high correlation between performance on the tone and letter tasks. However, if, as suggested by Podell et al. (1995) and Loeb and Alluisi (1984), sustained attention involves a multi-mechanistic balance between brain systems and hemispheres, a correlation might not be found for a verbal (letter) left-hemisphere task and a non-verbal (tone) right-hemisphere task.

Method

\section{Participants}

Human participants were recruited from the General (i.e., introductory) Psychology course at The University of Rhode Island. They ranged in age from 18.0 to 39.5 years $(\underline{M}=18.6, \underline{S D}=0.4)$. A total of 89 people took part in the study 
$($ females $=53$, males $=36)$. Participants were not paid; however, their participation in this study could be used to fulfill research participation requirements for their course.

Participants were screened by self-report for head injuries, hearing impairment, alcohol, caffeine and nicotine use, medications, diagnosed neurological impairments, learning disabilities and attention deficits, and handedness. Participants were excluded from this study for head injuries with periods of unconsciousness greater than 2 minutes, uncorrected hearing loss, alcohol, caffeine or nicotine consumption within the previous 4 hour period, the use of medications known to affect attentional processes, and diagnosed neurological impairments, learning disabilities and attention deficits.

\section{$\underline{\text { Apparatus }}$}

The CPT was run using a Gateway 2000 IBM compatible PC which allows sequential presentation of stimuli over stereo headphones with a $0.75 \mathrm{sec}$ onset to onset interval. During each $15 \mathrm{~min}$ test, 1200 stimuli were presented. There were 100 targets, to which the participants were required to respond with the press of a hand-held button. A target is constituted by a stimulus which is identical to the immediately preceding stimulus. Targets were presented at the average rate of one every $9 \mathrm{sec}$ for the entire test period in a semi-random sequence. No two targets were immediately sequential.

The computer program automatically scored the entire performance of the task for hits (correct identification of a target), false alarms (response to non-target stimuli), misses (non-response to a target), reaction time, and vigilance decrement (a reduction in performance with time spent on task). The program also automatically computes the hits, false alarms, misses, and reaction time for the five 3 min time segments of each task. 
$\underline{\text { Tasks }}$

There were two types of CPT tasks, an auditory letter and an auditory tone task. Auditory tasks were selected because there is reported to be better coupling of participant to signal than with visual tasks (Hatfield \& Loeb, 1968, as cited in Kastner, 1994). Each 15 minute task was divided into five three minute blocks of time (segments), containing an equal number of targets, for the purpose of determining vigilance decrements.

The auditory letter version of the CPT task consists of letters of the alphabet presented sequentially in semi-random fashion. A target is a letter immediately preceded by an identical letter. The auditory tone version consists of tones of the standard major diatonic musical scale (Randel, 1986) presented sequentially in semi-random fashion. A target was a tone immediately preceded by an identical tone. Target tones and the identical tones immediately preceding them were at least two whole notes above or below immediately surrounding tones for ease of detection by non-musicians. Participants were asked to respond to targets in each of these tasks by depressing a hand-held button once for each target. Letter and tone versions of the task were presented in counterbalanced order.

\section{Procedure}

Participants were tested individually on both the letter and tone version of the CPT. White noise from a speaker immediately behind the participant was used to screen out extraneous sounds that might affect performance measures. It was turned on prior to the participants arrival to allow for habituation before the testing procedure began. Immediately upon arrival, participants were asked to sign an informed consent form which 
was coded and filed separately to protect confidentiality. Code numbers, gender, and handedness were entered into the computer for scoring of the data. Each participant was then asked to complete a questionnaire designed to screen for head injuries, hearing impairment, alcohol, caffeine and nicotine use, medications, neurological impairments, learning disabilities, attention deficits, and handedness.

Following the questionnaire, the Visual Analog Mood Scales (VAMS) was administered. The VAMS is a paper and pencil task consisting of eight analog sub-scales representing eight different moods: tired, energetic, happy, sad, confused, angry, afraid, and tense. It is designed to be a brief, valid measure of internal mood states in clinical populations, including those for whom attention, comprehension, and verbal capabilities have been compromised (Stern, Arruda, Hooper, Wolfner, \& Morey, in press). It has been found to have high test-retest reliability, and excellent convergent and discriminant validity (Stern et al., in press).

Each mood sub-scale has a face at both ends of a vertical $100 \mathrm{~mm}$ line. The top face always represents neutral and is clearly labeled. The bottom face represents one of the moods and is clearly labeled with that mood. Participants were instructed to draw a horizontal line bisecting the $100 \mathrm{~mm}$ line at the point at which it most accurately described their mood at that time. The VAMS were hand scored with a standard metric ruler. The score represents the distance in $\mathrm{mm}$ from the neutral end of the line to the bisecting mark made by the participant.

At the beginning of the testing session, participants were seated in a comfortable chair and assisted in the placement of headphones, which they were allowed to adjust for 
comfort. They were given a hand-held response button which they used in their preferred hand. Instructions, explaining the task, were read verbatim to ensure equal treatment of participants. Overhead lighting was then extinguished. A $30 \mathrm{sec}$ practice session was administered prior to the first test session for each version of the task to allow mastery of the testing protocol and equipment.

Each individual was then tested for $15 \mathrm{~min}$ on either a letter or tone task. A $3 \mathrm{~min}$ rest session was provided before the start of the next task. Instructions for the second task were then read verbatim. After completing the practice session for the second task, the testing session of 15 min was begun.

Immediately following completion of the testing procedure, participants were asked to fill out a second VAMS for use in pre- and post-test mood analysis. Participants were then debriefed.

Data Analysis

Data used in this analysis is archived data obtained under IRB number $\mathrm{H}$ 9596112. All data collection was either conducted or supervised by this researcher. Data was analyzed by using SPSS/PC software. An a priori alpha level of .05 was used for all analyses.

Four separate mixed analyses of variance, 2 X ( 2 X 5) : presentation order X (task $\mathrm{X}$ block), were conducted for the following dependent variables: accuracy (percentage of correct responses), adjusted accuracy (accuracy adjusted using the Error Index formula), reaction time, and total number of false alarms. The use of a multivariate analysis of 
variance was rejected due to the correlations between measures and difficulty in interpretation of results.

Adjusted accuracy was calculated by the following method: $\left(1-I_{E}\right)^{*} 100$. The Error Index (Pigache, as cited in Davies \& Parasuraman, 1982) is derived as follows:

$$
\mathrm{I}_{\mathrm{E}}=\left(\mathrm{O}_{\mathrm{M}} / \mathrm{V}\right)+\left(2 \mathrm{C}_{\mathrm{O}} / \mathrm{W}\right)
$$

where $\mathrm{I}_{\mathrm{E}}=$ Error Index, $\mathrm{O}_{\mathrm{M}}=$ Number of omission errors or misses, $\mathrm{V}=$ Number of omission opportunities, $\mathrm{C}_{\mathrm{O}}=$ number of commission errors or false alarms, and $\mathrm{W}=$ number of commission opportunities. The use of $I_{E}$ corrects for motivational and response biases, and may be a purer measure of sensitivity decrement than either hits, misses, or false alarms taken alone. Response bias, for the purposes of this research, is measured by the Error Index formula.

Due to the exploratory nature of this study, the use of a Bonferoni correction for family wise error during follow-up planned comparisons was rejected.

In addition, paired $t$ tests were used to analyze vigilance decrement (the change in accuracy from beginning to end of task), adjusted vigilance decrement (the change in adjusted accuracy from beginning to end of task), the latency decrement (the change in reaction time from beginning to end of task), and the change in false alarm rate (change in number of false alarms from beginning to end of task) by task.

Correlations of performance measures (accuracy, adjusted accuracy, false alarms and reaction times) between tasks and within tasks were undertaken using Pearson's $r$ as a means of determining the comparability of these tasks as measures of sustained attention. 
This study was conducted under IRB approval (H 9596-112), which has been granted for the purpose of the study of sustained attention.

\section{Results}

\section{Accuracy}

Table 1 shows the means and standard deviations for accuracy on the letter and tone tasks by block and presentation order. The results of a mixed analysis of variance, 2 $\mathrm{X}$ (2 X5): order X (task X block), for accuracy found a significant main effect for task, $\mathrm{F}(1,87)=29.81, \underline{\mathrm{p}}<.001, \mathrm{ES}=.26$, Power $=1.0$, with the letter task having a significantly higher level of accuracy than the tone task. There was also a significant main effect for block, $\underline{F}(1,87)=37.36, \underline{p}<.001, E S=.30$, Power $=1.0$. Simple comparisons found significant differences between block 1 and block $2, \underline{t}=8.18, \underline{p}<.001$, block 1 and block $3, \underline{\mathrm{t}}=8.59, \underline{\mathrm{g}}<.001$, block 1 and block $4, \underline{\mathrm{t}}=10.08, \underline{\mathrm{p}}<.001$, block 1 and block 5 , $\underline{\mathrm{t}}=8.85, \underline{\mathrm{p}}<.001$, block 2 and block $4, \underline{\mathrm{t}}=3.69, \underline{\mathrm{p}}<.001$, block 2 and block $5, \underline{\mathrm{t}}=2.87$, $\mathrm{p}<.01$, and block 3 and block $4, \underline{\mathrm{t}}=2.41, \mathrm{p}<.05$. In all cases, the earlier blocks had the higher levels of accuracy. (See Figure 1)

A significant interaction effect was found for order $X$ task $X$ block, $\underline{F}(4,348)=$ $4.51, \mathrm{p}<.001, \mathrm{ES}=.05$, Power $=.94$. Upon follow-up testing, this was found to be due to a significant order $\mathrm{X}$ block interaction for the tone task $\underline{\mathrm{F}}(4,348)=3.71, \mathrm{p}<.01$. Simple effects tests found this attributable to significant differences by order for block 1 , 
$\underline{F}(1,87)=7.86, \underline{p}<.01$, and block $2, \underline{F}(1,87)=4.41, \underline{p}<.05$. For both block 1 and block 2, accuracy on the tone task for the presentation order letter-tone was significantly higher than for the order tone-letter. (See Figures 2 and 3)

Adjusted Accuracy

Table 2 shows the means and standard deviations for adjusted accuracy on the letter and tone tasks by block and presentation order. Table 3 shows the means and standard deviations for the error index which were used in the calculation of the adjusted accuracy scores.

The results of a mixed analysis of variance, $2 \times(2 \times 5)$ : order $\times$ ( task $x$ block), found a significant main effect for order, $\mathrm{E}(1,87)=4.41, \underline{\mathrm{p}}<.05, \mathrm{ES}=.05$, Power $=.54$, with the order letter-tone having significantly higher levels of adjusted accuracy than the order tone-letter. A significant main effect was found for task, $\underline{F}(1,87)=41.83, \underline{p}<.001$, $\mathrm{ES}=.33$, Power $=1.0$, with the letter task having significantly higher levels of adjusted accuracy than the tone task. A significant main effect was also found for block, $\underline{F}(4,348)=27.37, \underline{p}<.001, E S=.24$, Power $=1.0$. Simple comparisons found significant differences between block 1 and block $2, \underline{t}=7.25, \underline{p}<.001$, block 1 and block $3, \underline{\mathrm{t}}=7.33, \underline{\mathrm{p}}<.001$, block 1 and block $4, \underline{\mathrm{t}}=8.42, \underline{\mathrm{p}}<.001$, block 1 and block 5 , $\underline{\mathrm{t}}=7.66, \mathrm{p}<.001$, block 2 and block $4, \underline{\mathrm{t}}=2.69, \mathrm{p}<.01$, block 2 and block $5, \underline{\mathrm{t}}=2.01$, $\underline{p}<.05$, and block 3 and block $4, \underline{t}=2.08, \underline{p}<.05$. In all cases, the earlier the block, the higher the level of adjusted accuracy. (See Figure 4)

A significant order $X$ task $X$ block interaction, $\underline{F}(4,348)=6.03, \underline{p}<.001$, was found to be accounted for by a significant interaction of order $\mathrm{X}$ block for the tone task, 
$\underline{F}(1,87)=14.04, \underline{p}<.001$. Simple effects tests indicated that this interaction could be accounted for by significant differences for order $X$ block $1, \underline{F}(1,87)=14.04, \underline{p}<.001$, and order $\mathrm{X}$ block $2, \underline{\mathrm{F}}(1,87)=9.60, \underline{\mathrm{p}}<.01$. For both block 1 and block 2 , the presentation order letter-tone was found to have significantly higher levels of adjusted accuracy on the tone task than order tone-letter. (See Figures 5 and 6)

\section{$\underline{\text { Reaction Time }}$}

Table 4 shows the means and standard deviations for reaction time on the letter and tone tasks by block and presentation order. The results of a mixed analysis of variance, $2 \mathrm{X}(2 \mathrm{X} 5)$ : order $\mathrm{X}$ (task $\mathrm{X}$ block), for reaction time found a significant main effect for block, $\underline{\mathrm{F}}(4,348)=39.80, \underline{\mathrm{p}}<.001, \mathrm{ES}=.31$, Power $=1.0$. Simple comparisons found significant differences between block 1 and block $2, \underline{t}=-6.96, \underline{p}<.001$, block 1 and block $3, \underline{\mathrm{t}}=-11.98, \mathrm{p}<.001$, block 1 and block $4, \underline{\mathrm{t}}=-11.02, \underline{\mathrm{p}}<.001$, block 1 and block $5, \underline{\mathrm{t}}=-9.85, \underline{\mathrm{p}}<.001$, and block 2 and block $3, \underline{\mathrm{t}}=-2.81, \underline{\mathrm{p}}<.01$. In all cases, the earlier the block, the faster the reaction time. (See Figure 7)

A significant interaction was found for order $\mathrm{X}$ block, $\underline{\mathrm{F}}(4,348)=3.47, \mathrm{p}<.01$, $\mathrm{ES}=.04$, Power $=.86$. Simple effects tests found significant differences by block for the letter-tone presentation order as follows: block 1 and block $2, \underline{t}=-11.63, \underline{p}<.001$, block 1 and block $3, \underline{\mathrm{t}}=-9.54, \underline{\mathrm{p}}<.001$, block 1 and block $4, \underline{\mathrm{t}}=-7.40, \underline{\mathrm{p}}<.001$, block 1 and block $5, \underline{\mathrm{t}}=-8.60, \underline{\mathrm{p}}<.001$, and block 4 and block $5, \underline{\mathrm{t}}=-2.43, \underline{\mathrm{p}}<.05$. In all cases, the earlier the block, the faster the reaction time. Significant differences by block were also found for the tone-letter order as follows: block 1 and block $2, \underline{t}=-2.67, \underline{p}<.0 I$, 
block 1 and block $3, \underline{\mathrm{t}}=-7.63, \underline{\mathrm{p}}<.001$, block 1 and block $4, \underline{\mathrm{t}}=-8.17, \underline{\mathrm{p}}<.001$, block 1 and block $5, \underline{\mathrm{t}}=-5.54, \underline{\mathrm{p}}<.001$, block 2 and block $3, \underline{\mathrm{t}}=-2.94, \underline{\mathrm{p}}<.01$, block 2 and block $4, \underline{\mathrm{t}}=-2.27, \underline{\mathrm{p}}<.05$, and block 3 and block $5, \underline{\mathrm{t}}=-1.99, \underline{\mathrm{p}}<.05$. In all cases, the earlier the block, the faster the reaction time.

A significant interaction for reaction time was also found for task $\mathrm{X}$ block, $\underline{F}(4,348)=3.88, \underline{p}<.01, E S=.02$, Power $=.43$. Simple effects tests found that this interaction effect was attributable to a significant difference between the letter and tone task for block $1, \underline{t}=-2.24, \underline{p}<.05$, with reaction time on the letter task being significantly faster than on the tone task. (See Figures 8 and 9)

\section{False Alarms}

Table 5 shows the means and standard deviations for false alarms on the letter and tone tasks by block and presentation order. The results of a mixed analysis of variance for number of false alarms found a significant main effect for order, $\underline{F}(1,87)=13.82$, $\mathrm{p}<.001, \mathrm{ES}=.14$, Power $=.96$, with the tone-letter presentation order having a significantly greater number of false alarms than the letter-tone order. A significant main effect was found for task, $\underline{F}(1,87)=23.62, \underline{p}<.001, E S=.21$, Power $=1.0$, with the tone task having significantly more false alarms than the letter task. A significant main effect for block was also found, $\underline{\mathrm{F}}(4,348)=11.50, \underline{\mathrm{p}}<.001, \mathrm{ES}=.12$, Power $=1.0$. Simple comparisons indicate the following significant differences: block 1 and block 3, $\underline{\mathrm{t}}=3.80, \underline{\mathrm{p}}<.001$, block 1 and block $4, \underline{\mathrm{t}}=3.78, \underline{\mathrm{p}}<.001$, block 1 and block $5, \underline{\mathrm{t}}=4.39$, 
$\underline{\mathrm{p}}<.001$, block 2 and block $3, \underline{\mathrm{t}}=3.15, \underline{\mathrm{p}}<.01$, block 2 and block $4, \underline{\mathrm{t}}=3.25, \underline{\mathrm{p}}<.001$, and block 2 and block $5, \underline{t}=3.95, \underline{p}<.001$. In all cases, the earlier the block, the more false alarms. (See Figure 10)

A significant interaction was found for order by task, $\underline{\mathrm{F}}(1,87)=14.52, \mathrm{p}<.001$, $\mathrm{ES}=.14$, Power $=.96$. The significance of this interaction is attributable to a significant tone by order effect, $\underline{\mathrm{F}}(1,87)=14.31, \mathrm{p}<.001$, with the presentation order tone-letter having a significantly greater number of false alarms than the letter-tone order.

A significant interaction was found for order by block, $\underline{\mathrm{F}}(4,348)=3.62, \mathrm{p}<.01$, $\mathrm{ES}=.04$, Power $=.87$. Significant differences were found by order for block 1 , $\underline{\mathrm{F}}(1,176)=10.78, \underline{\mathrm{p}}<.001$, block $2, \underline{\mathrm{F}}(1,176)=13.30, \mathrm{p}<.001$, block $3, \underline{\mathrm{F}}(1,176)=$ $8.22, \underline{\mathrm{p}}<.01$, block $4, \underline{\mathrm{F}}(1,176)=5.73, \underline{\mathrm{p}}<.05$, and block $5, \underline{\mathrm{F}}(1,176)=9.84, \underline{\mathrm{p}}<.01$. In all cases, the tone-letter presentation order had significantly more false alarms than the letter-tone order.

A significant interaction effect was found for task X block, $\underline{F}(4,348)=7.75$, $\mathrm{p}<.001, \mathrm{ES}=.08$, Power $=1.0$. Significant differences were found for task for block 1, $\underline{F}(1,176)=20.78, \underline{p}<.001$, block $2, \underline{F}(1,176)=26.71, \underline{p}<.001$, block $3, \underline{F}(1,176)=$ $12.90, \underline{\mathrm{p}}<.001$, block $4, \underline{\mathrm{F}}(1,176)=11.58, \underline{\mathrm{p}}<.001$, and block $5, \underline{\mathrm{F}}(1,176)=13.67$, $\underline{p}<.001$. In all cases, the tone task had significantly more false alarms than the letter task. A significant interaction was also found for order $\mathrm{X}$ task $\mathrm{X}$ block, $\underline{\mathrm{F}}(4,348)=$ $4.48, \underline{p}<.01, \mathrm{ES}=.05$, Power $=.94$. Follow-up testing indicated a significant interaction of order $\mathrm{X}$ block for the tone task, $\underline{\mathrm{F}}(4,348)=4.52, \underline{\mathrm{p}}<.001$. Simple effects tests showed that this interaction for the tone task was due to significant differences by order for 
block $1, \underline{\mathrm{F}}(1,87)=13.76, \underline{\mathrm{p}}<.001$, block $2, \underline{\mathrm{F}}(1,87)=19.25, \underline{\mathrm{p}}<.001$, block 3 , $\underline{F}(1,87)=10.19, \underline{p}<.01$, and block $4, \underline{F}(1,87)=6.84, \underline{p}<.01$. In all cases, the toneletter presentation order had significantly more false alarms on the tone task than did the letter-tone order. (See Figures 11 and 12)

\section{Decrements}

Tables 1-5 show the decrements for accuracy, adjusted accuracy, reaction time, response bias (as measured by the error index), and number of false alarms, respectively. The decrements for accuracy, adjusted accuracy, reaction time, and false alarms can also be seen in Figures 1-12. Significant vigilance decrements were found for accuracy on both the letter, $\underline{\mathrm{t}}=6.66, \underline{\mathrm{p}}<.001$, and tone task, $\underline{\mathrm{t}}=5.95, \mathrm{p}<.001$, as shown by the significant decreases in overall performance found between blocks 1 and 5 on these measures, with the letter task having a larger absolute decrement than the tone task. However, between tasks, the vigilance decrement was not significantly different. Significant vigilance decrements were also found for both tasks on adjusted accuracy, with the letter task, $\underline{\mathrm{t}}=6.51, \mathrm{p}<.001$, having a slightly larger absolute decrement than the tone task, $\underline{\mathrm{t}}=4.59$, $p<.001$. The difference between the tasks was found to be non-significant.

Latency decrements were also found for both tasks as evidenced by the significant increase in reaction time from blocks 1 to 5 , with the letter task, $\underline{t}=9.19, \underline{p}<.001$, showing a larger absolute decrement than the tone task, $\mathrm{t}=5.05, \mathrm{p}<.001$. The latency decrement between the two tasks was also significant, $\underline{t}=3.04, \underline{p}<.01$.

Performance improved over the course of the tone task for false alarms, with the number of false alarms decreasing as the task progressed, $\underline{t}=4.32, \underline{p}<.001$, as can be 
seen by the significant decrease in number of false alarms between blocks 1 and 5 . There was no significant difference for change in false alarms between tasks. Both tasks showed a significant change in response bias, as measured by the error index, from blocks 1 to 5 , with the response bias increasing slightly more for letters, $\underline{\mathrm{t}}=6.51, \mathrm{p}<.001$, than for tones, $\underline{\mathrm{t}}=4.57, \underline{\mathrm{p}}<.001$. The differences in response bias between tasks was nonsignificant

The letter task demonstrated a significant latency decrement by order, with the letter-tone order showing a greater increase in reaction time than the tone-letter order, $\underline{F}(1,87)=5.94, \underline{p}<.05$. A latency decrement was not found for tones.

Vigilance and adjusted vigilance decrements were found to be significant for the tone task by order, but not for the letter task. The presentation letter-tone showed greater decrement on tones than did the order tone-letter on accuracy, $\underline{F}(1,87)=9.00, \underline{p}<.01$, and adjusted accuracy, $\underline{\mathrm{F}}(1,87)=13.68, \underline{\mathrm{p}}<.001$.

The tone task also showed a significant change in response bias by order, with the letter-tone order having the greater increase in response bias than the tone-letter order, $\underline{F}(1,87)=13.69, \underline{p}<.001$. The letter task did not have a significant change in response bias by order. In addition, the tone task, but not the letter task, displayed a significant difference by order in the number of false alarms from beginning to end of the task. The presentation order tone-letter showed a decrease in the number of false alarms, whereas the letter-tone order showed an increase in false alarms, $\underline{F}(1,87)=7.50, \underline{p}<.01$. 


\section{Correlational Analyses}

Table 6 shows the within subjects correlations for accuracy by block between the letter and tone tasks. The following correlations between the letter and tone task were found to differ significantly for accuracy: block $2, \underline{r}=.23, \underline{p}<.05$, block $3, \underline{r}=.23$, $\underline{\mathrm{p}}<.05$, block $4, \underline{\mathrm{r}}=.38, \underline{\mathrm{p}}<.001$, block $5, \underline{\mathrm{r}}=.47, \underline{\mathrm{p}}<.001$, and total accuracy, $\underline{\mathrm{r}}=.24$, $\mathrm{p}<.05$.

Table 7 shows the within subjects correlations for adjusted accuracy by block between the letter and tone tasks. Significant correlations for adjusted accuracy between tasks were: block $1, \underline{\mathrm{r}}=.22, \underline{\mathrm{p}}<.05$, block $2, \underline{\mathrm{r}}=.24, \underline{\mathrm{p}}<.05$, block $3, \underline{\mathrm{r}}=.23, \underline{\mathrm{p}}<.05$, block $4, \underline{\mathrm{r}}=.42, \underline{\mathrm{p}}<.001$, block $5, \underline{\mathrm{r}}=.48, \underline{\mathrm{p}}<.001$, and total adjusted accuracy, $\underline{\mathrm{r}}=.26$, $\underline{p}<.01$.

Table 8 shows the within subjects correlations for reaction time by block between the letter and tone tasks. Significant correlations for reaction time between tasks were: block $1, \underline{r}=.71, \underline{p}<.001$, block $2, \underline{r}=.56, \underline{p}<.001$, block $3, \underline{r}=.72, \underline{p}<.001$, block 4 , $\underline{\mathrm{r}}=.68, \underline{\mathrm{p}}<.001$, block $5, \underline{\mathrm{r}}=.74, \underline{\mathrm{p}}<.001$, and total reaction time, $\underline{\mathrm{r}}=.85, \underline{\mathrm{p}}<.001$.

Table 10 shows the within subjects correlations for false alarms by block between the letter and tone tasks. There were no significant correlations for false alarms between tasks.

Table 11 shows the correlations within the letter task. Within the letter task, the following correlations were significant for the total task: accuracy and adjusted accuracy, $\underline{\mathrm{r}}=.78, \underline{\mathrm{p}}<.001$, and accuracy and reaction time, $\underline{\mathrm{r}}=-.21, \underline{\mathrm{p}}<.05$. 
Table 12 shows the correlations within the tone task. Within the tone task, the following correlations were significant for the total task: accuracy and adjusted accuracy, $\underline{\mathrm{r}}=.92, \underline{\mathrm{p}}<.001$, accuracy and reaction time, $\underline{\mathrm{r}}=-.27, \underline{\mathrm{p}}<.01$, and adjusted accuracy and reaction time, $\underline{r}=-.23, \underline{p}<.05$. False alarms were not correlated with any other measure for either task.

Table 13 shows the correlations for total performance measures collapsed over task. Collapsed over task, the following correlations were significant: total accuracy and total adjusted accuracy, $\underline{\mathrm{r}}=.82, \underline{\mathrm{p}}<.001$, and total accuracy and total reaction time, $\underline{\mathrm{r}}=-.23, \underline{\mathrm{p}}<.01$.

\section{Discussion}

The significant change in accuracy and adjusted accuracy from beginning to end of task for both the letter and tone tasks indicates that significant decrements in vigilance and adjusted vigilance are important features of high-event rate, successive CPTs and constitute a decrease in the ability to sustain attention over time. Although significant differences between tasks were found for accuracy and adjusted accuracy, with the tone task seemingly the harder of the two, the failure to find a significant difference between tasks in either the vigilance or the adjusted vigilance decrement suggests that the two tasks can be considered to be measuring the same pattern of decreasing attentional abilities even though they differ significantly in level of difficulty. However, the particular facets of vigilance performance that affect this pattern of decrement may differ by task (Parasuraman, 1984). 
Due to the parallel nature of the vigilance decrements for the two tasks, this would also seem to indicate that the use of either task in a clinical setting would be able to adequately sample this overall decrease, eliminating the need to test on both types of stimuli. The use of one task rather than two would be both cost and time effective. Currently, most clinics using CPTs to diagnose attention deficits do so by using one sensory modality (e.g., visual or auditory) and one type of stimulus (e.g., cognitive or sensory) with no reliable reason to believe that the results would be comparable if task parameters were changed or a client was tested differently in another setting. The development of tests that are comparable, but differ along a meaningful dimension, such as verbal/non-verbal, would make CPTs more valuable in a clinical setting with varying patient needs. For example, if a patient's verbal abilities had been compromised, a comparable non-verbal test would be a better selection.

The tone task evidenced significant decrements on all measures over time, whereas the letter task showed decrements on all measures except false alarm rate. Between tasks, however, the only significant differences found were in latency decrement and for the change in number of false alarms. Understanding of this latter finding is complicated by the fact that both tasks elicited relatively few false alarms and demonstrated very different patterns of response by order, i.e., whether the task was presented first or second. The letter task showed a greater number of false alarms for the presentation order tone-letter, that is, letter second, by the end of task, but no change for the letter-tone order, that is, letter first. The tone task, by contrast, showed a decrease in the number of false alarms for the tone-letter order, that is, tone first, and an increase in the letter-tone order, that is, 
tone second. These contrasting patterns may be the result of fatigue and/or declining attentional capabilities as the greater number of false alarms comes on the second task in both cases.

Although the letter task had significantly faster reaction times for the first 6 minutes of the test than did the tone task regardless of presentation order, the advantage was lost by the third block, with the latency decrement increasing rapidly for letters. For the final 9 minutes of the test, the letter task had significantly slower reaction times than the tone task. This is interesting in light of the strong, positive correlation between tests for reaction time, and weak, but significant, negative association within tests between reaction time and accuracy, which indicates that as accuracy increases, reaction times decrease. As the letter task is the easier of the two tasks and has higher accuracy scores, one would expect to find faster reaction times. However, this correlation was heavily influenced by the large differences between tasks in the first 6 minutes, with the letter task being much faster than the tone task.

An interesting finding of this study was that for the tone task, there was a significant difference in accuracy, adjusted accuracy, and false alarms for order by block. Accuracy and adjusted accuracy both showed better performance for the letter-tone presentation order in blocks 1 and 2 than for the tone-letter order. However, the initial advantage gained by this presentation order was no longer evident after the 6 th minute of the task. This would seem to indicate that although the tone task was harder than the letter task, some learning had taken place during the letter task that facilitated performance on the tone task in the first 6 minutes. By contrast, the performance on the tone task when 
presented first showed an initial disadvantage, but less of a decrement over the duration of the task, indicating that learning may have occurred within the first 6 minutes of the tone task to approximately match that achieved when letters were presented first. By the end of the tone task, there was no significant difference in either accuracy or adjusted accuracy by order of presentation.

It is uncertain whether the learning that appears to take place in the tone task is specific to tones or is general to the task. We do not see the same pattern of improvement for the letter task when tones comes first which seems to indicate that practice on tones did not enhance performance on letters in the same way that practice on letters seems to have enhanced performance on tones. If we assume that the fatigue factor is the same for both presentation orders, it would appear that the learning that occurs on the tone task may be specific to that stimulus type and may be reflective of learning relative to discriminability or to changes in expectancy. The learning on the letter task, by contrast, appears to be generalizable to tones.

The tone task showed greater numbers of false alarms in all blocks than did the letter task, with a pronounced order effect in which the tone-letter (i.e. tone first) presentation order had significantly more false alarms than did the letter-tone order (i.e. tone second) for all blocks. The number of false alarms was much higher for the initial two blocks than for the final three blocks, indicating an initial response bias on the tone task to button press. However, this early response bias was no longer evident by block three, and there was no significant difference in response bias between the two tasks by the end of 
testing. The greater number of false alarms in the first 6 minutes of the task might also indicate greater difficulty in discriminating between tones.

This finding might reflect the relative difference in difficulty between the two tasks, with the early disadvantage for the tone task disappearing as the result of learning or changes in expectancy. A possible explanation for the low number of false alarms for the letter task might be that the task is not sensitive enough to detect false alarms due to the ceiling effect found on the easier task. Therefore, actual differences in false alarms between tasks may be artifactual.

The results of this study pose an interesting question regarding the reasons for the failure to find a difference in the adjusted vigilance decrement between tasks. The purpose of using the Error Index formula was to remove response bias from the accuracy scores. This was based upon the assumption that when the tendency to button press was greater, participants would achieve some of their hits due to random button presses, thus receiving inflated accuracy scores. Because the false alarm rate was significantly higher for the tone task than the letter task, adjusting for accuracy should affect the tone task more than the letter task, increasing the likelihood of finding a difference between tasks for the adjusted vigilance decrement. However, no significant difference in decrement was found for the adjusted accuracy scores.

Contrary to expectations, significant vigilance and adjusted vigilance decrements were found for both the cognitive (letter) and sensory (tone) tasks. See et al. (1994) have suggested that CPTs using sensory stimuli would show vigilance decrements due to changes in sensitivity, whereas those using cognitive stimuli would not, although 
cautioning that more research was needed on high-event rate, successive tasks. The results of this study suggest that although vigilance decrements reflective of decreases in sensitivity may not be found on cognitive CPTs at lower event rates or for simultaneously presented stimuli, this may not be true for tasks with more rapid, sequential processing requirements.

Vigilance decrements may be conceptualized as reflecting (a) sensitivity decrements due to habituation or decreased perceptual sensitivity; plus (b) changes in the response biases over the course of the CPT; plus (c) a decrease in attentional resources or the effort necessary to coordinate arousal and expectancy (Parasuraman, 1984). By adjusting accuracy by removing response bias, an adjusted vigilance decrement would represent sensitivity decrement plus decrease in attentional resources. If, as some researchers have indicated (See et al, 1994), a sensitivity decrement is found for sensory tasks but not for cognitive tasks, a possible explanation for the parallel pattern of the adjusted vigilance decrement scores for the letter and tone versions of the task is that the decrement found in the letter task represents a greater decrease in attentional resources than does the tone task.

Sensitivity, $d$, is generally measured in relation to the number of false alarms and is calculated as a function of miss rate minus false alarm rate (unlike response bias which is calculated by adding miss rate and false alarm rate). Due to the floor effect for false alarms for the letter task, it was not possible to determine the sensitivity for this measure for use in comparison to that of the tone task. Future research would be useful in looking at this potential difference between tasks and in partialing out both sensitivity decrement and 
response bias in order to get a purer look at decreases in attentional resources. In order to accomplish this, it is recommended that the letter task be made equal in difficulty to that of the tone task, allowing for more accurate comparison.

In general, the correlations between the letter and tone versions of the task for accuracy and adjusted accuracy were low, but significant, explaining very little of the variance between the two tasks. Correlations for reaction time indicate a strong, significant relationship between the two tasks on this measure. Significance of these correlations indicate that the two tasks are equivalent when used with a normal, young adult population. In addition, it should be noted that the correlations between the tasks are stronger for the final 6 minutes of each task, allowing for experience with the tone task to balance the relative difference in difficulty. However, caution needs to be exercised due to the overall weak relationships between tasks on accuracy and adjusted accuracy and the significant differences found between the two tests in the mixed analyses of variance.

Within the letter task, a weak, but significant, negative association was found between accuracy and reaction time; as accuracy increased, reaction time decreased or got faster. As expected, there was a strong, positive association between accuracy and adjusted accuracy. Within the tone task, somewhat stronger, negative associations were found between reaction time and accuracy and adjusted accuracy, whereas a strong, positive relationship was found for accuracy and adjusted accuracy. This latter finding might be considered somewhat surprising considering the significant difference in the number of false alarms between tasks. 
Collapsed across tasks, a weak, but significant, negative relationship was found for total reaction time and total accuracy. As accuracy increased, reaction time decreased or got faster. A strong, positive association was found for accuracy and adjusted accuracy. If criterion validity for two versions of a CPT that differ only on stimulus type and construct validity for a unified single mechanism of sustained attention are to be upheld, we would need a high correlation between performance on the letter and tone tasks. Although significant correlations were found for these two tasks, only for reaction time was the correlation a strong one. If, however, as suggested by Podell et al. (1995) and Loeb and Alluisi (1984), sustained attention involves a multi-mechanistic balance between brain systems and hemispheres, a strong correlation might not be found for a verbal (letter) tasks and a non-verbal (tone) task.

These results would suggest that reaction time might represent a more unified process underlying attention, such as arousal, which would fit nicely with Prather and Kaplan's (in press) model of attention, whereas overall performance measures (such as accuracy) which capture perceptual sensitivity, expectancy-based criteria, and effort may reflect a more multi-mechanistic model, such as that of Podell et al. (1995) or Loeb and Alluisi (1984).

In conclusion, the results of this study indicate the relative equivalency of these two versions of auditory, high-event rate, successive cognitive and sensory CPT tasks albeit still showing intriguing differences. An important finding was that of the parallel patterns of vigilance decrement for the two tasks. However, until the question of a possible difference in the reasons for the difference in vigilance and adjusted vigilance 
decrement between the two tasks can be addressed, they should not be viewed as measuring the same construct in clinical or research settings. More research is needed to clarify the relationships between these variables and the ways in which they interact differently for cognitive and sensory stimuli.

Unlike other studies that have found significant differences between performance measures differing on stimulus type and/or modality, the results of this study have indicated that it is possible to construct comparable cognitive and sensory tasks if enough care is taken to ensure that all other task parameters are equivalent. Although it is not known which parameter or combination of parameters is most important when designing comparable tasks, the following parameters were carefully matched in this study: modality (i.e., auditory); onset-to-onset time; duration of task; duration of individual stimulus presentation; ratio of targets to non-targets; presentation order of targets within the total pattern of stimuli; volume of presentation; computerized scoring; equipment used; instructions; and setting. However, even with careful construction of matched tasks, one can detect differences between cognitive and sensory tasks. Future research would be useful in the determination of critical task parameters and combinations of parameters and in the design of carefully constructed, comparable tasks that differ only in stimulus type or modality for use in a clinical setting with differing patient needs. 


\section{References}

Azar, B. (1995, November). Attitude affects memory, decisions, and performance. Monitor, p. 27.

Damasio, A. R. (1995). Descartes Error. New York: Avon.

Davies, D. R., \& Parasuraman, R. (1982). Vigilance and the brain. In P. Warr (Series Ed.) \& Davies, D. R. \& Parasuraman, R. (Vol. Eds.), Organizational and Occupational Psychology: Vol. 8. The Psychology of Vigilance (pp. 181-207). London: Academic Press.

Halperin, J. M., Sharma, V., Greenblatt, E., \& Schwartz, S. T. (1991). Assessment of the continuous performance test: Reliability and validity in a nonreferred sample. Psychological Assessment: A Journal of Consulting and Clinical Psychology, 3 (4), 603-608.

Hallowell, E. M., \& Ratey, J. J. (1994). Driven to Distraction. New York: Pantheon. Kastner, M. P., (1994). A pilot study to develop and compare performance on a verbal visual, and an abstract visual continuous performance test. Unpublished master's thesis, University of Rhode Island, Kingston.

Lang, P. J. (1995). The emotion probe: Studies of motivation and attention. American Psychologist, 50 (5), 372-385.

Loeb, M., \& Alluisi, E. A. (1984). Theories of vigilance. In D. H. Holding (Series Ed.) \& J. S. Warm (Vol. Ed.), Wiley Series on Studies in Human Performance: Vol. 4. Sustained Attention in Human Performance (pp. 179-205). Chichester: John Wiley \& Sons, Ltd. 
Luria, A. R. (1973). The Working Brain: An Introduction to Neuropsychology. Basic Books.

McKiernan, K. A., \& Reeve, N. M., (1995). The influence of emotion on sustained attention. Unpublished manuscript. University of Rhode Island, Kingston.

Parasuraman, R. (1984). The psychobiology of sustained attention. In D. H. Holding (Series Ed.) \& J. S. Warm (Vol. Ed.), Wiley Series on Studies in Human Performance: Vol. 4. Sustained Attention in Human Performance (pp. 61-101). Chichester: John Wiley \& Sons, Ltd.

Podell, K., Lovell, M., Zimmerman, M., \& Goldberg, E. (1995). The cognitive bias task and lateralized frontal lobe functions in males. Journal of Neuropsychiatry, 7 (4), 491-501.

Posner, M. I., \& Dehaene, S. (1994). Attentional networks. TINS, 17 (2), 75-79.

Prather, P., \& Kaplan, E. (in press). Attention and its disorders: Facts physiology and a theoretical framework. Discussions in Neurosciences.

Randel, D. M., Ed. (1986). The New Harvard Dictionary of Music. Cambridge, MA: Harvard University Press.

Revelle, W. (1992). Differences in personality and motivation. In A. Baddeley \& W. Weiskrantz (Eds.), Attention: Selection Awareness and Control: A Tribute to Donald Broadbent (pp. 346-373). Oxford: Clarendon Press.

See, J. E., Howe, S. R., Warm, J. S., \& Dember, W. N. (1995). Meta-analysis of the sensitivity decrement in vigilance. Psychological Bulletin, 117 (2), 230-249. 
Stern, R. A., Arruda, J. E., Hooper, C. R., Wolfner, G. D., \& Morey, C. E. (in press). Visual analog mood scales to measure internal mood state in neurologically impaired patients: description and initial validity evidence. Aphasiology.

Thayer, R. E. (1989). The Biopsychology of Mood and Arousal. New York: Oxford.

Tomporowski, P. D, \& Tinsley, V. (1994), Effects of target probability and memory demands on the vigilance of adults with and without mental retardation. American Journal on Retardation, 98 (6), 688-703.

Warm, J. S. (1984). An introduction to vigilance. In D. H. Holding (Series Ed.) \& J. S. Warm (Vol. Ed.), Wiley Series on Studies in Human Performance: Vol. 4. Sustained Attention in Human Performance (pp. 1-14, 323-331). Chichester: John Wiley \& Sons, Ltd.

Whitehead, R. (1991). Right hemisphere processing superiority during visual sustained attention. Journal of Cognitive Neuroscience, $3,329-334$. 
Table 1

Means and Standard Deviations for Accuracy on the Letter and Tone Tasks by Block and Presentation Order

\section{Letters}

Block 1 Block 2 Block 3 Block 4 Block 5 Total Vig Dec Letter-Tone

$\begin{array}{cccccccc}\mathrm{M} & 97.02 & 89.33 & 89.41 & 88.85 & 89 & 91.47 & 8.02 \\ \mathrm{SD} & 3.56 & 8.89 & 10.94 & 11.45 & 13.88 & 7.76 & 12.85 \\ \mathrm{~N} & 45 & 45 & 45 & 45 & 45 & 45 & 45\end{array}$

Tone-Letter

$\begin{array}{cccccccc}\mathrm{M} & 93.57 & 89.07 & 84.78 & 85.72 & 83.08 & 87.83 & 10.49 \\ \mathrm{SD} & 14.99 & 17.19 & 18.27 & 17.94 & 17.32 & 15.52 & 13.36 \\ \mathrm{~N} & 44 & 44 & 44 & 44 & 44 & 44 & 44\end{array}$

Total

$\begin{array}{cccccccc}\text { M } & 95.32 & 89.2 & 87.12 & 87.3 & 86.07 & 89.67 & 9.24 \\ \text { SD } & 10.92 & 13.56 & 15.11 & 15.01 & 15.87 & 12.29 & 13.09 \\ \text { N } & 89 & 89 & 89 & 89 & 89 & 89 & 89\end{array}$

Tones

Block 1 Block 2 Block 3 Block 4 Block 5 Total Vig Dec Tone-Letter

$\begin{array}{cccccccc}\text { M } & 83.41 & 77.26 & 78.24 & 74.44 & 78.31 & 78.53 & 5.1 \\ \text { SD } & 16.02 & 18.49 & 17.37 & 20.53 & 19.45 & 16.17 & 13.92 \\ \text { N } & 44 & 44 & 44 & 44 & 44 & 44 & 44\end{array}$

Letter-Tone

$\begin{array}{cccccccc}\mathrm{M} & 91.67 & 84.78 & 81.11 & 76.67 & 76.94 & 82.43 & 14.72 \\ \mathrm{SD} & 11.43 & 15.15 & 19.62 & 18.62 & 19.2 & 14.69 & 16.24 \\ \mathrm{~N} & 45 & 45 & 45 & 45 & 45 & 45 & 45\end{array}$

Total

$\begin{array}{cccccccc}\mathrm{M} & 87.58 & 81.06 & 79.69 & 75.57 & 77.62 & 80.5 & 9.97 \\ \mathrm{SD} & 14.42 & 17.21 & 18.49 & 19.51 & 19.23 & 15.48 & 15.81 \\ \mathrm{~N} & 89 & 89 & 89 & 89 & 89 & 89 & 89\end{array}$




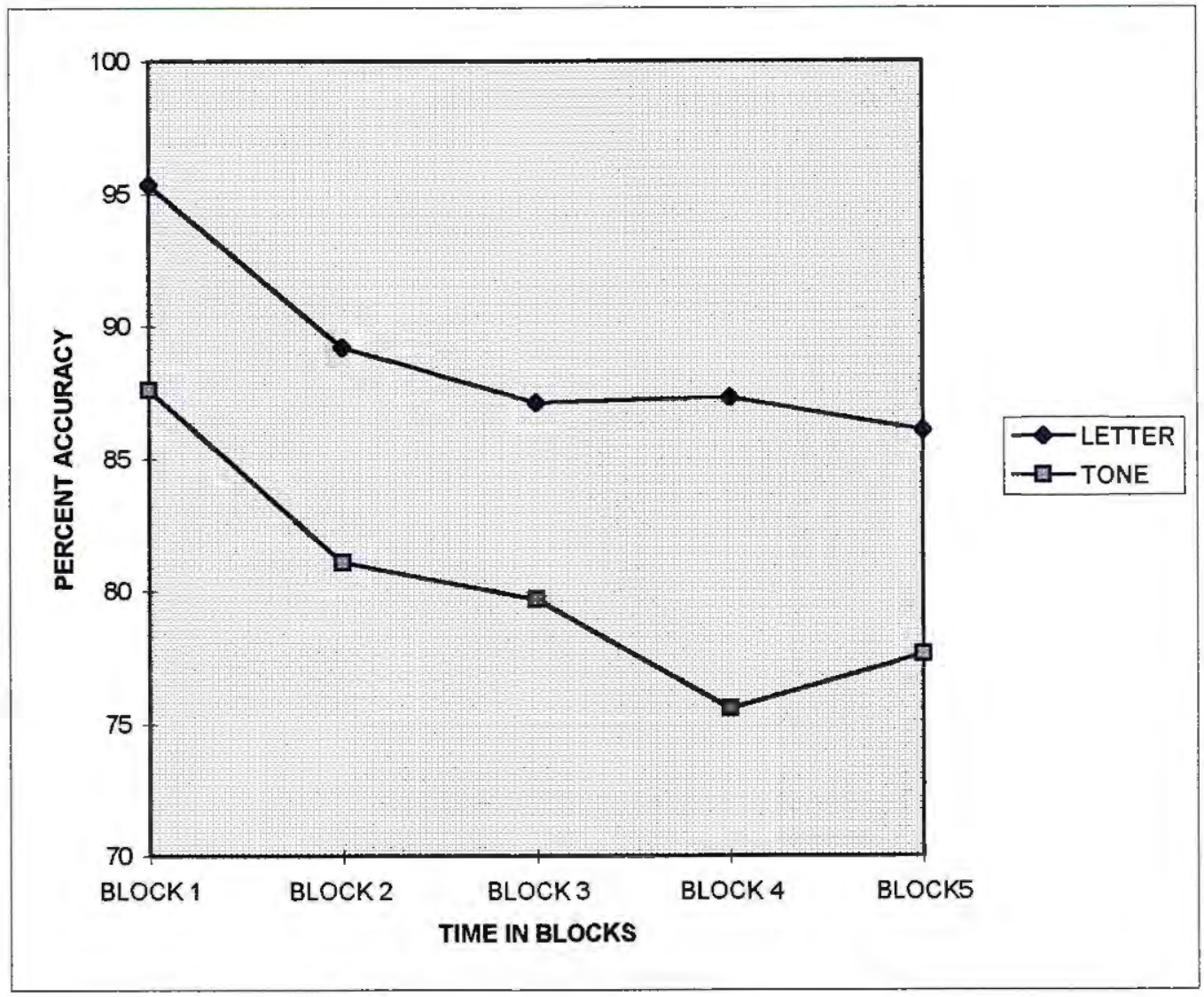

Figure 1. Mean accuracy by block for the letter and tone tasks. 

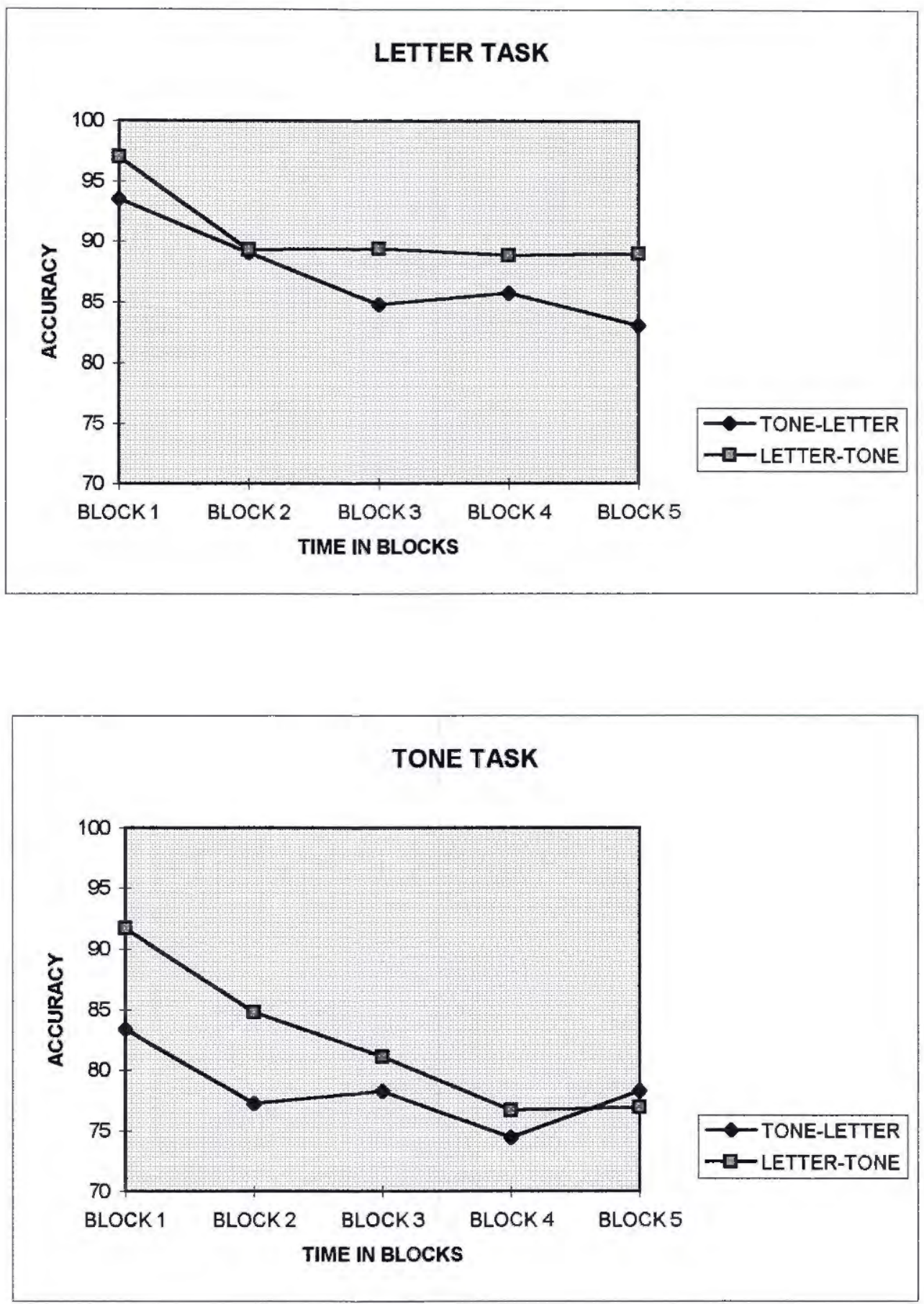

Figure 5. Mean accuracy by order by block for the letter and tone tasks. 

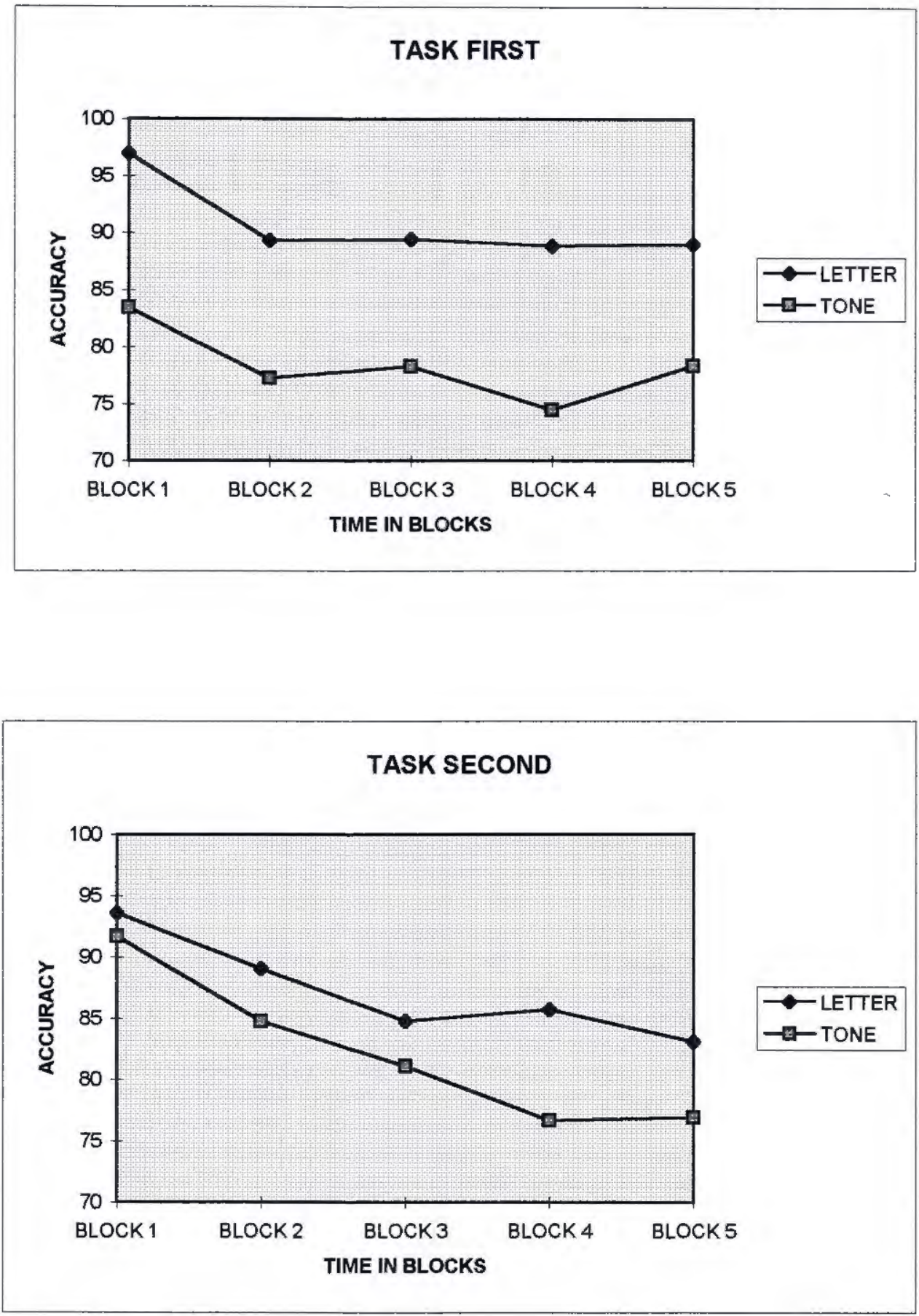

Figure 9. Mean accuracy by block for task when the task comes first or second in the presentation order. 
Table 2

Means and Standard Deviations for Adjusted Accuracy on the Letter and Tone Tasks by Block and Presentation Order

Letters

Block 1 Block 2 Block $3 \quad \overline{\text { Block } 4}$ Block 5 Total Adj Dec Letter-Tone

$\begin{array}{cccccccc}\text { M } & 95.87 & 88.36 & 88.46 & 88.04 & 88.15 & 89.78 & 7.72 \\ \text { SD } & 4.07 & 9.09 & 11.34 & 11.74 & 13.97 & 10.04 & 13.08 \\ \text { N } & 45 & 45 & 45 & 45 & 45 & 45 & 45\end{array}$

Tone-Letter

$\begin{array}{cccccccc}\text { M } & 92.51 & 88.33 & 83.95 & 84.98 & 82.12 & 86.38 & 10.39 \\ \text { SD } & 15 & 17.22 & 18.2 & 18.18 & 17.05 & 17.13 & 13.14 \\ \text { N } & 44 & 44 & 44 & 44 & 44 & 44 & 44\end{array}$

Total

$\begin{array}{cccccccc}\text { M } & 94.21 & 88.34 & 86.23 & 86.53 & 85.17 & 88.1 & 9.04 \\ \text { SD } & 11 & 13.64 & 15.21 & 15.25 & 15.77 & 14.17 & 13.11 \\ \text { N } & 89 & 89 & 89 & 89 & 89 & 89 & 89\end{array}$

Tones

Block 1 Block 2 Block 3 Block 4 Block 5 Total Adj Dec Tone-Letter

$\begin{array}{llllllll}\text { M } & 76.14 & 70.09 & 73.26 & 69.94 & 74.24 & 72.73 & 1.9\end{array}$

$\begin{array}{llllllll}\text { SD } & 20.5 & 22.82 & 21.07 & 23.4 & 21.51 & 21.86 & 13.48\end{array}$

$\begin{array}{llllllll}\mathrm{N} & 44 & 44 & 44 & 44 & 44 & 44 & 44\end{array}$

Letter-Tone

$\begin{array}{llllllll}\text { M } & 89.67 & 83.04 & 79.84 & 75.29 & 75.73 & 80.71 & 13.94\end{array}$

$\begin{array}{llllllll}\text { SD } & 12.76 & 16.11 & 20.5 & 19.34 & 20.25 & 17.79 & 16.99\end{array}$

$\begin{array}{llllllll}\mathrm{N} & 45 & 45 & 45 & 45 & 45 & 45 & 45\end{array}$

Total

$\begin{array}{cccccccc}\text { M } & 82.98 & 76.64 & 76.59 & 72.65 & 74.99 & 76.77 & 7.98 \\ \text { SD } & 18.25 & 20.66 & 20.93 & 21.49 & 20.77 & 19.83 & 16.43 \\ \text { N } & 89 & 89 & 89 & 89 & 89 & 89 & 89\end{array}$


Table 3

Means and Standard Deviations for the Error Index on the Letter and Tone Tasks by Block and Presentation Order

$\underline{\text { Letters }}$

Block 1 Block 2 Block 3 Block 4 Block 5 Total Rsp Bias Letter-Tone

$\begin{array}{cccccccc}\mathrm{M} & 4.13 & 11.64 & 11.54 & 11.96 & 11.85 & 10.22 & 7.72 \\ \mathrm{SD} & 4.07 & 9.09 & 11.34 & 11.74 & 13.97 & 10.04 & 13.08 \\ \mathrm{~N} & 45 & 45 & 45 & 45 & 45 & 45 & 45\end{array}$

Tone-Letter

$\begin{array}{cccccccc}\text { M } & 7.49 & 11.67 & 16.05 & 15.02 & 17.88 & 13.62 & 10.39 \\ \text { SD } & 15 & 17.22 & 18.24 & 18.18 & 17.05 & 17.14 & 13.14 \\ \mathrm{~N} & 44 & 44 & 44 & 44 & 44 & 44 & 44\end{array}$

Total

$\begin{array}{cccccccc}\text { M } & 5.79 & 11.66 & 13.77 & 13.47 & 14.13 & 11.92 & 9.04 \\ \text { SD } & 11 & 13.64 & 15.21 & 15.25 & 15.77 & 13.59 & 13.1 \\ \text { N } & 89 & 89 & 89 & 89 & 89 & 89 & 89\end{array}$

Tones

Block 1 Block 2 Block 3 Block 4 Block 5 Total Rsp Bias Tone-Letter

$\begin{array}{cccccccc}\mathrm{M} & 23.88 & 29.91 & 26.74 & 30.06 & 25.76 & 27.27 & 1.87 \\ \mathrm{SD} & 20.58 & 22.82 & 21.07 & 23.4 & 21.51 & 21.88 & 13.53 \\ \mathrm{~N} & 44 & 44 & 44 & 44 & 44 & 44 & 44\end{array}$

Letter-Tone

$\begin{array}{llllllll}\text { M } & 10.33 & 16.96 & 20.16 & 24.71 & 24.27 & 19.29 & 13.94\end{array}$

$\begin{array}{llllllll}\text { SD } & 12.76 & 16.12 & 20.5 & 19.34 & 20.25 & 13.69 & 16.99\end{array}$

$\begin{array}{llllllll}\mathrm{N} & 45 & 45 & 45 & 45 & 45 & 45 & 45\end{array}$

Total

$\begin{array}{cccccccc}\text { M } & 17.03 & 23.36 & 23.41 & 27.35 & 25.01 & 23.28 & 7.97 \\ \text { SD } & 18.3 & 20.66 & 20.93 & 21.49 & 20.78 & 17.79 & 16.4 \\ \text { N } & 89 & 89 & 89 & 89 & 89 & 89 & 89\end{array}$




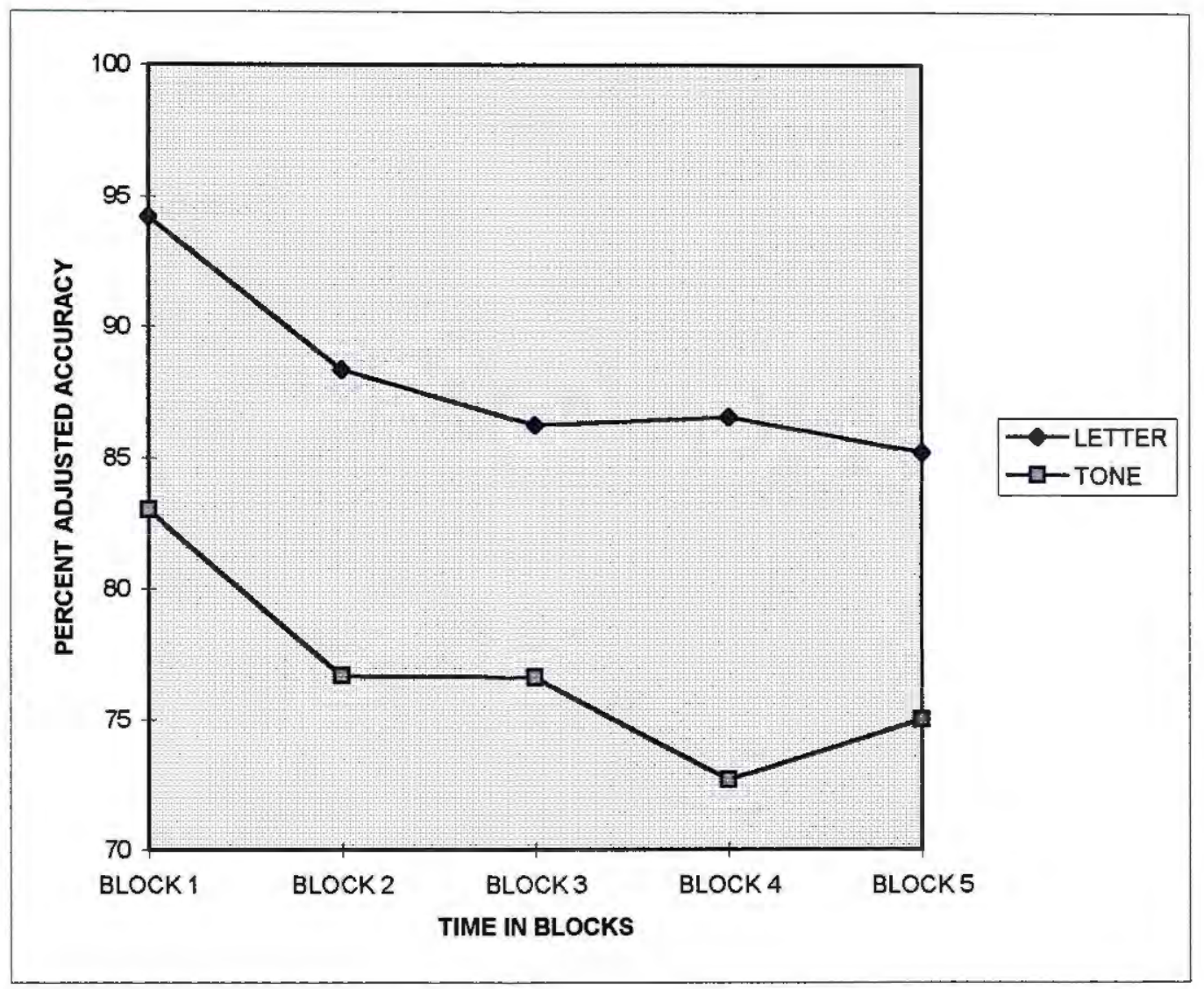

Figure 4. Mean adjusted accuracy by block for the letter and tone tasks. 

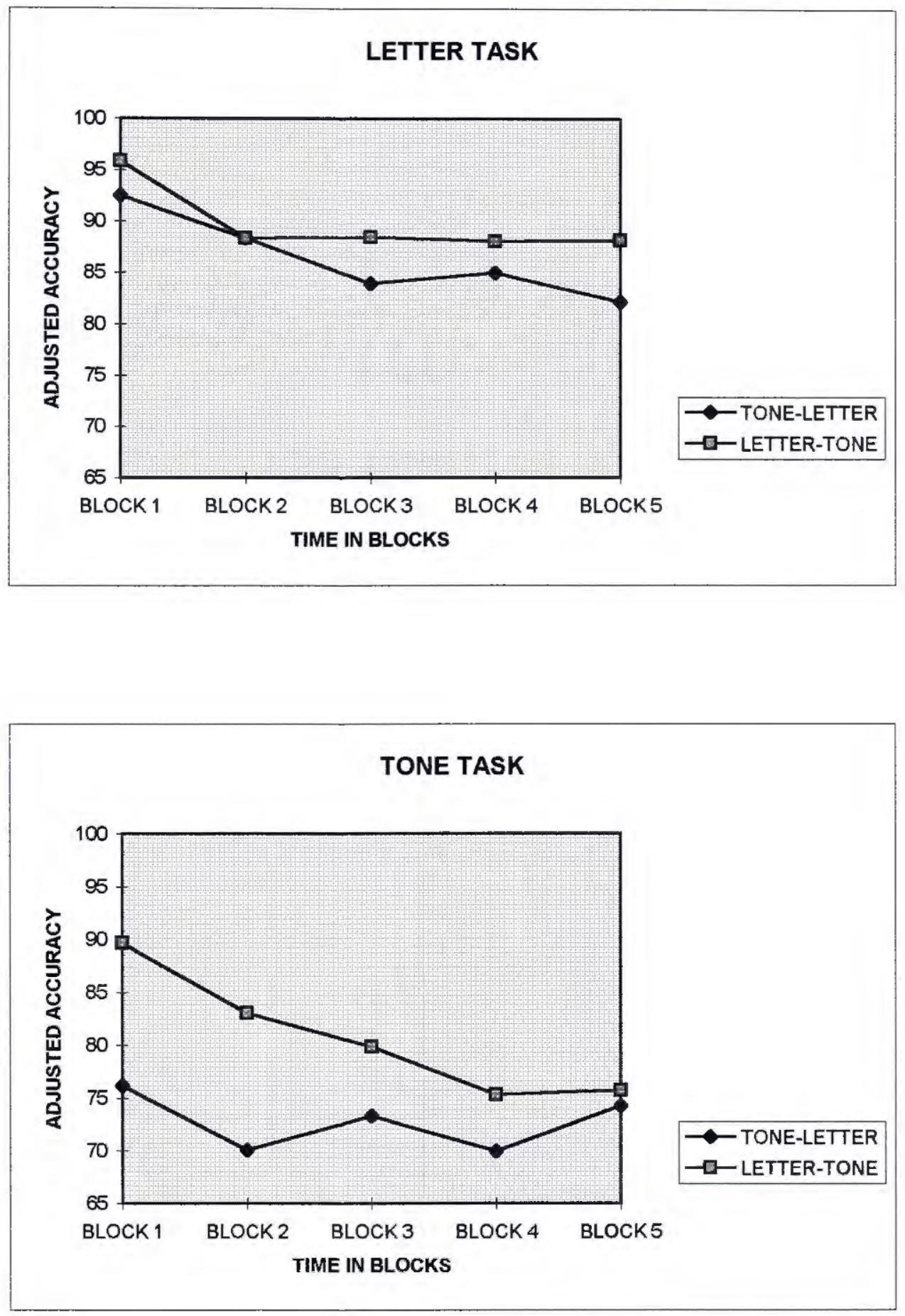

Figure 5. Mean adjusted accuracy by order by block for the letter and tone tasks. 

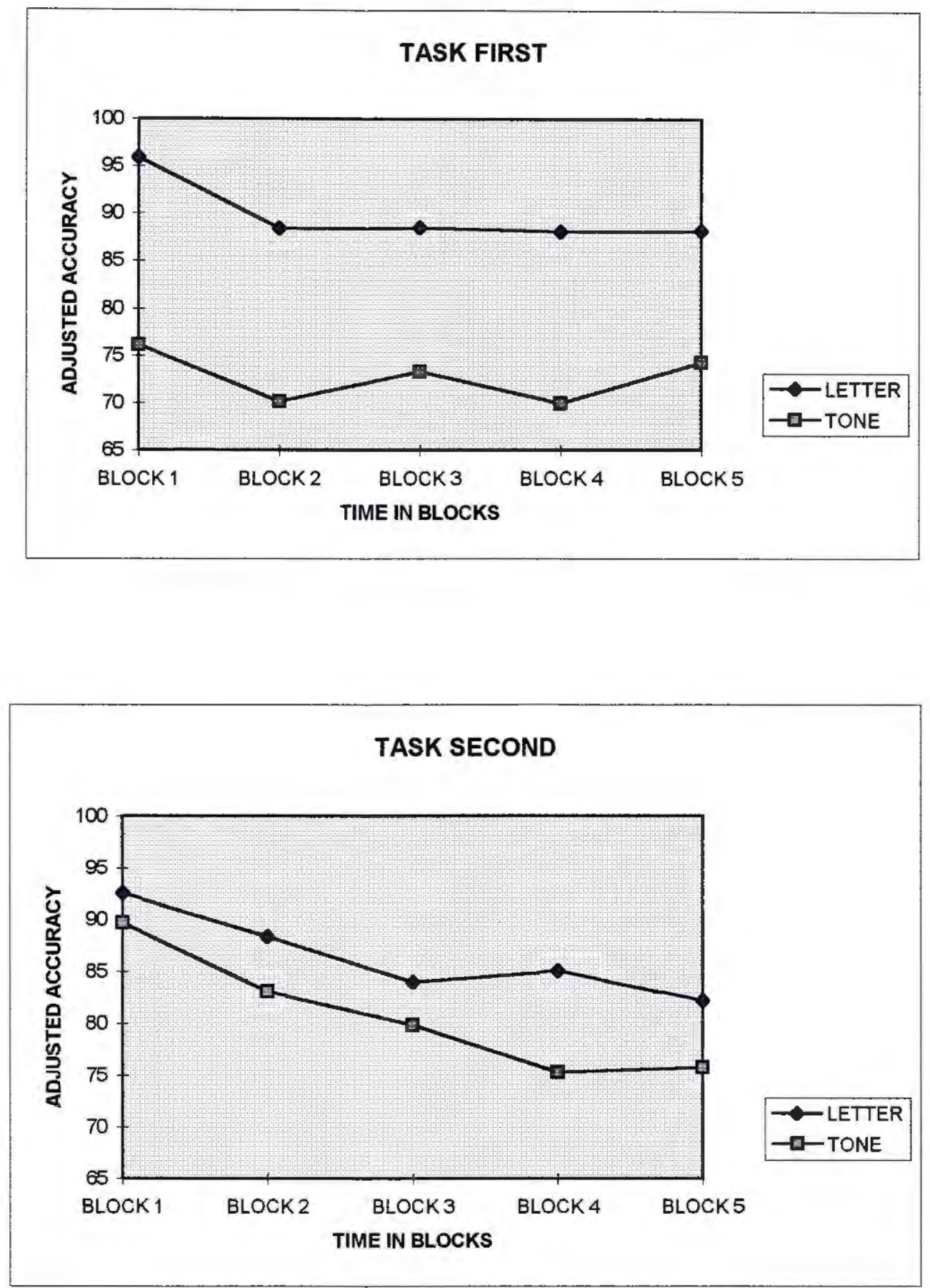

Figure 6. Mean adjusted accuracy by block for task when the task comes first or second in the presentation order. 
Table 4

Means and Standard Deviations for Reaction Time on the Letter and Tone Tasks by Block and Presentation Order

Letters

Block 1 Block 2 Block 3 Block 4 Block 5 Total Lat Dec Letter-Tone

$\begin{array}{cccccccc}\text { M } & 626.49 & 695.63 & 706.91 & 697.02 & 715.96 & 688.88 & 89.48 \\ \text { SD } & 88.22 & 88.31 & 90.99 & 102.76 & 102.49 & 86.21 & 75.2 \\ \text { N } & 45 & 45 & 45 & 45 & 45 & 45 & 45\end{array}$

Tone-Letter

$\begin{array}{llllllll}\text { M } & 642.66 & 664.72 & 704.49 & 715.87 & 695.34 & 688.11 & 52.68\end{array}$

$\begin{array}{llllllll}\text { SD } & 93.5 & 131.32 & 86.44 & 111.4 & 96.37 & 86.14 & 66.83\end{array}$

Total

$\begin{array}{llllllll}\mathrm{N} & 44 & 44 & 44 & 44 & 44 & 44 & 44\end{array}$

$\begin{array}{cccccccc}\text { M } & 634.48 & 680.35 & 705.72 & 706.34 & 705.77 & 688.5 & 71.28 \\ \text { SD } & 90.72 & 112.11 & \mathbf{8 8 . 2 7} & 106.93 & 99.49 & 85.69 & 73.16 \\ \text { N } & 89 & 89 & 89 & 89 & 89 & 89 & 89\end{array}$

Tones

Block 1 Block 2 Block 3 Block 4 Block 5 Total Lat Dec Tone-Letter

$\begin{array}{cccccccc}\text { M } & 651.86 & 692.61 & 709.79 & 701.28 & 692 & 689.57 & 40.14 \\ \text { SD } & 103.64 & 103.28 & 106.82 & 110.44 & 112.76 & 96.37 & 89.14 \\ \text { N } & 44 & 44 & 44 & 44 & 44 & 44 & 44\end{array}$

Letter-Tone

$\begin{array}{cccccccc}\mathrm{M} & 651.72 & 696.25 & 691.37 & 683.02 & 691.12 & 681.24 & 39.4 \\ \mathrm{SD} & 95.23 & 100.99 & 114.25 & 104.42 & 101.29 & 96.64 & 57.28 \\ \mathrm{~N} & 45 & 45 & 45 & 45 & 45 & 45 & 45\end{array}$

Total

$\begin{array}{cccccccc}\text { M } & 651.79 & 694.45 & 700.47 & 692.04 & 691.55 & 685.36 & 39.77 \\ \text { SD } & 98.91 & 101.56 & 110.4 & 107.22 & 106.5 & 96.05 & 74.32 \\ \text { N } & 89 & 89 & 89 & 89 & 89 & 89 & 89\end{array}$




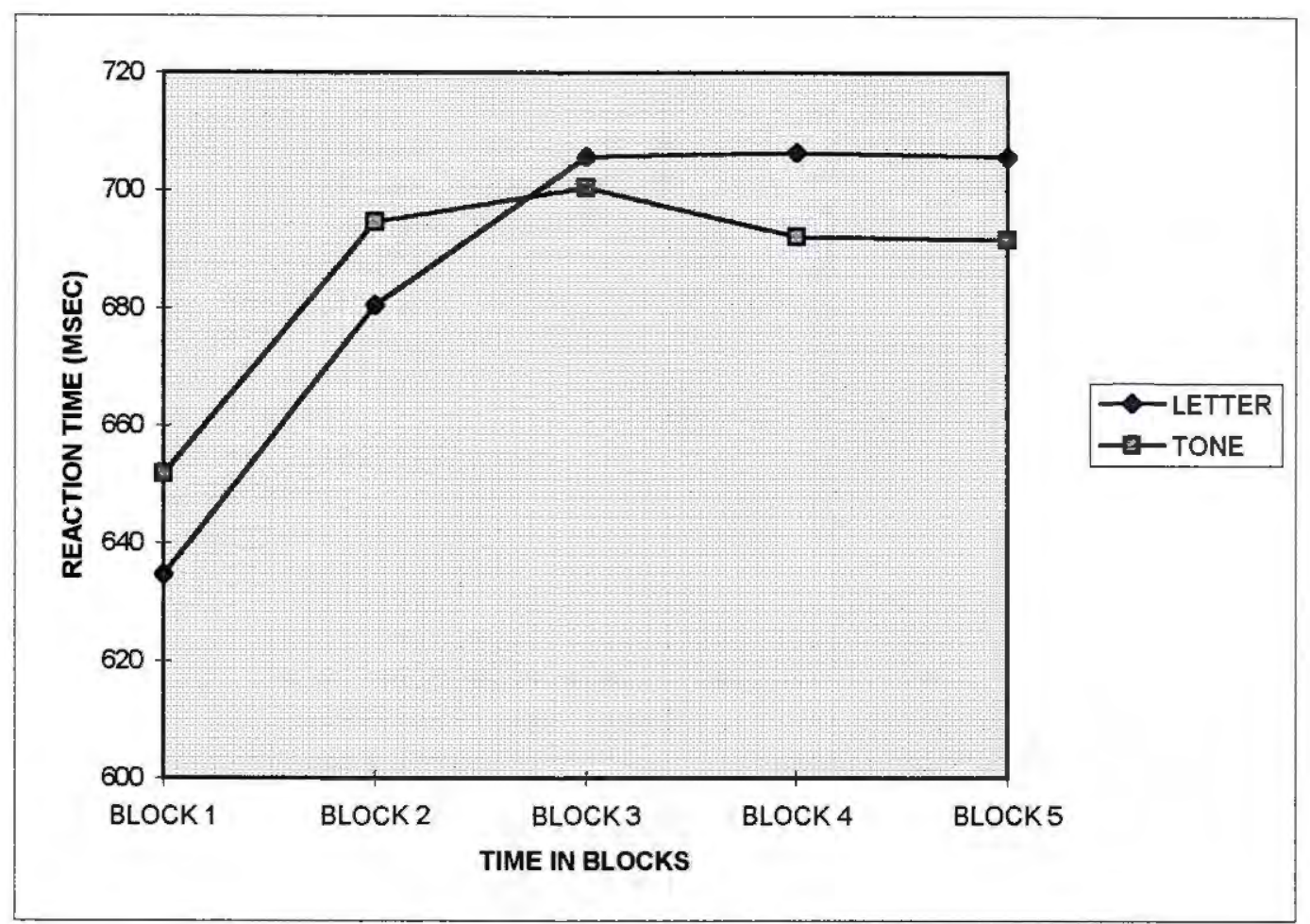

Figure 7. Mean reaction time by block for the letter and tone tasks. 

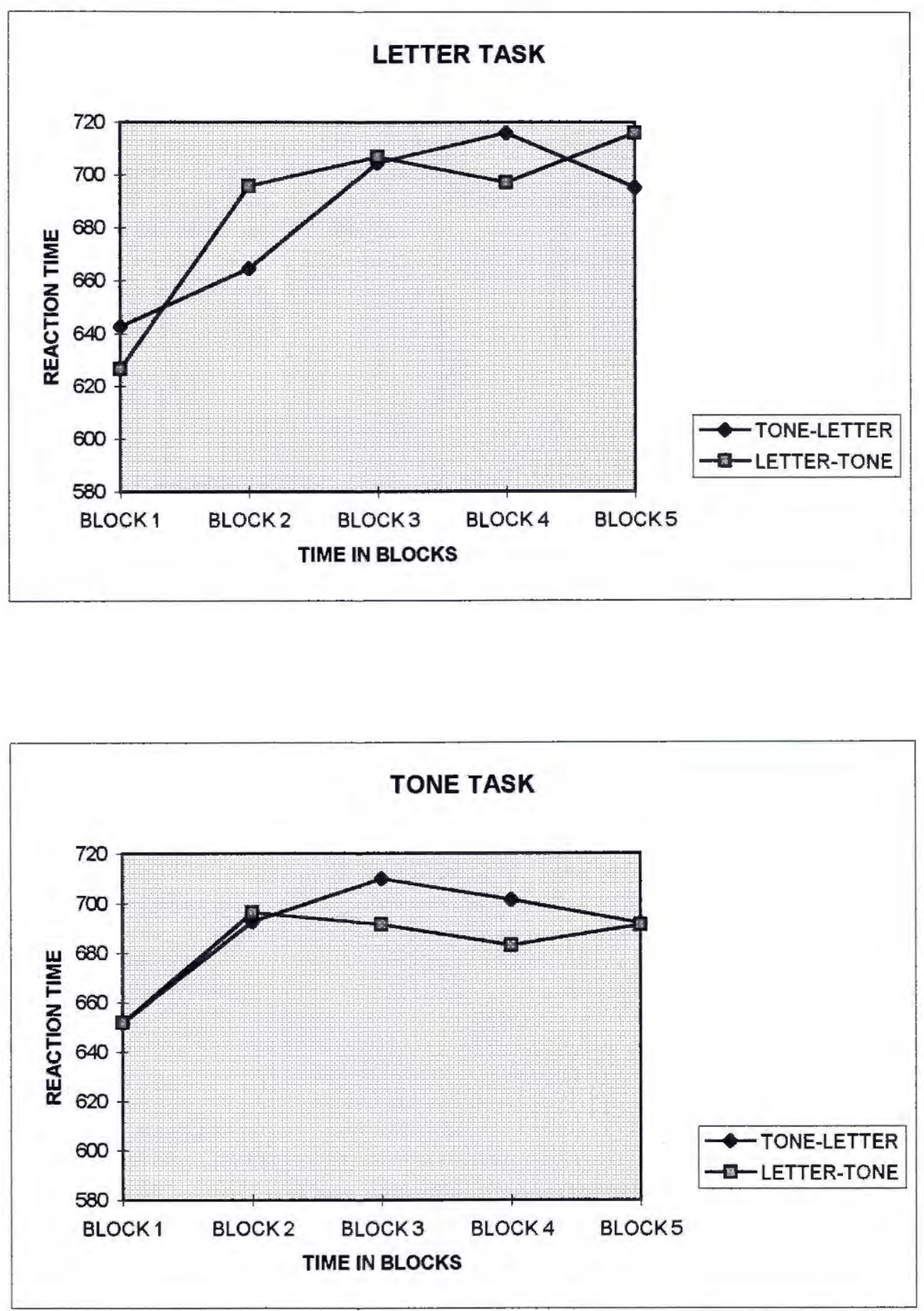

Figure 8. Mean reaction time by order by block for the letter and tone tasks. 

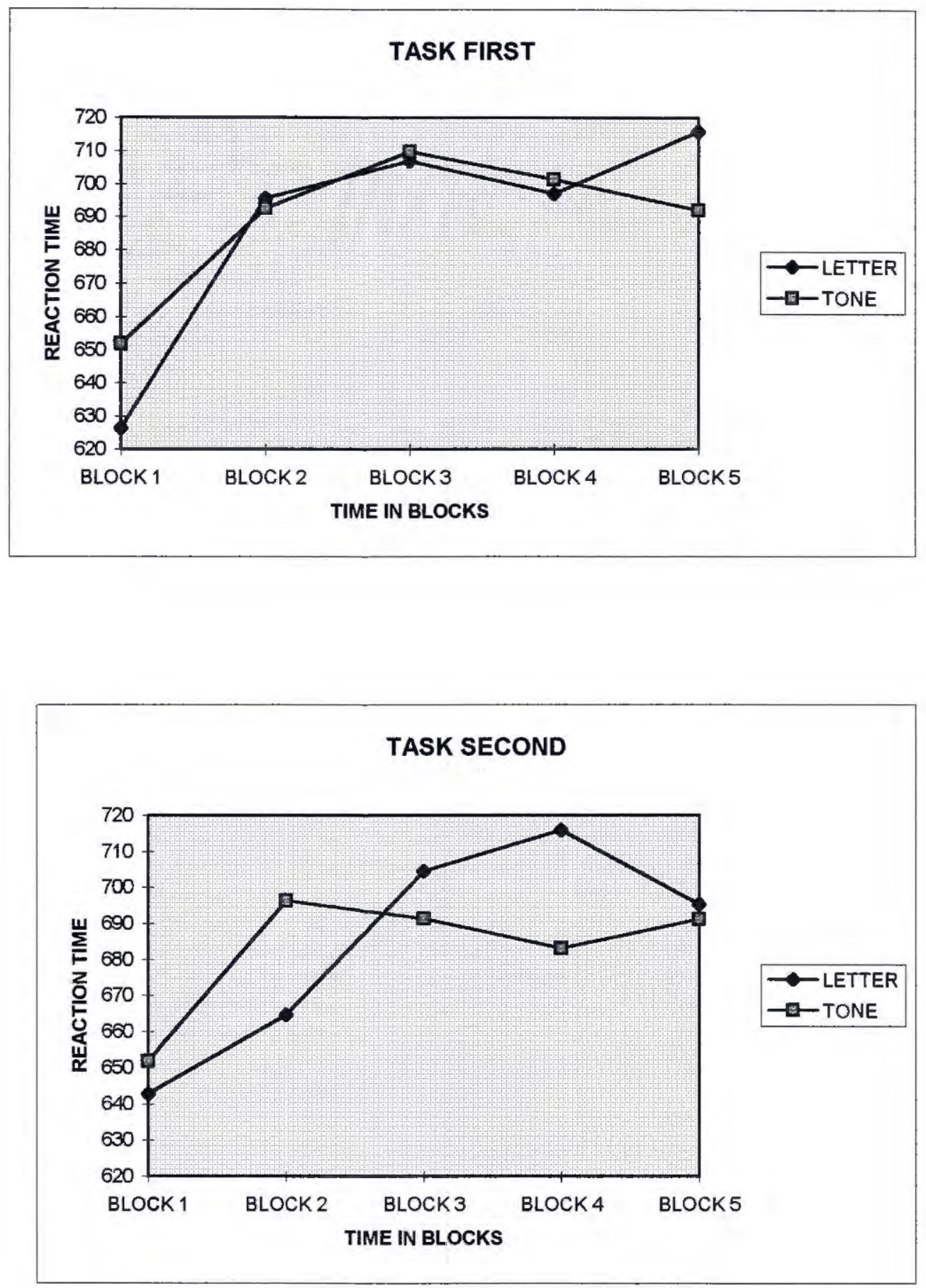

Figure 9. Mean reaction time by block for task when the task comes first or second in the presentation order. 
Table 5

Means and Standard Deviations for Number of False Alarms on the Letter and Tone Tasks by Block and Presentation Order

Letters

Block 1 Block 2 Block 3 Block 4 Block 5 Total FA Diff

Letter-Tone

$\begin{array}{cccccccc}\text { M } & 0.5 & 0.5 & 0.5 & 1 & 0.5 & 3 & 0 \\ \text { SD } & 0.7 & 0.7 & 0.7 & 1.4 & 0.7 & 2.8 & 0 \\ \text { N } & 45 & 45 & 45 & 45 & 45 & 45 & 45\end{array}$

Tone-Letter

$\begin{array}{cccccccc}\mathrm{M} & 0 & 0 & 0.5 & 0.5 & 0.5 & 1.5 & -0.5 \\ \mathrm{SD} & 0 & 0 & 0.7 & 0.7 & 0.7 & 0 & 0.7 \\ \mathrm{~N} & 44 & 44 & 44 & 44 & 44 & 44 & 44\end{array}$

Total

$\begin{array}{cccccccc}\text { M } & 0 & 0.5 & 0.5 & 0.5 & 0 & 1.5 & 0 \\ \text { SD } & 0 & 0.7 & 0.7 & 0.7 & 0 & 0 & 0 \\ \text { N } & 89 & 89 & 89 & 89 & 89 & 89 & 89\end{array}$

Tones

Block 1 Block 2 Block 3 Block 4 Block 5 Total FA Diff Tone-Letter

$\begin{array}{cccccccc}\mathrm{M} & 3 & 2 & 2 & 1.5 & 1.5 & 10 & 1.5 \\ \mathrm{SD} & 0 & 2.8 & 0 & 0.7 & 0.7 & 3.5 & 2.1 \\ \mathrm{~N} & 44 & 44 & 44 & 44 & 44 & 44 & 44\end{array}$

Letter-Tone

$\begin{array}{cccccccc}\text { M } & 1 & 0 & 1 & 1 & 1.5 & 4.5 & -0.5 \\ \text { SD } & 1.4 & 0 & 0 & 0 & 2.1 & 3.5 & 2.1 \\ \text { N } & 45 & 45 & 45 & 45 & 45 & 45 & 45\end{array}$

Total

$\begin{array}{cccccccc}\mathrm{M} & 2.5 & 1 & 1 & 1.5 & 1.5 & 7.5 & 1 \\ \mathrm{SD} & 0.7 & 1.4 & 0 & 0.7 & 1.4 & 3.5 & 2.8 \\ \mathrm{~N} & 89 & 89 & 89 & 89 & 89 & 89 & 89\end{array}$




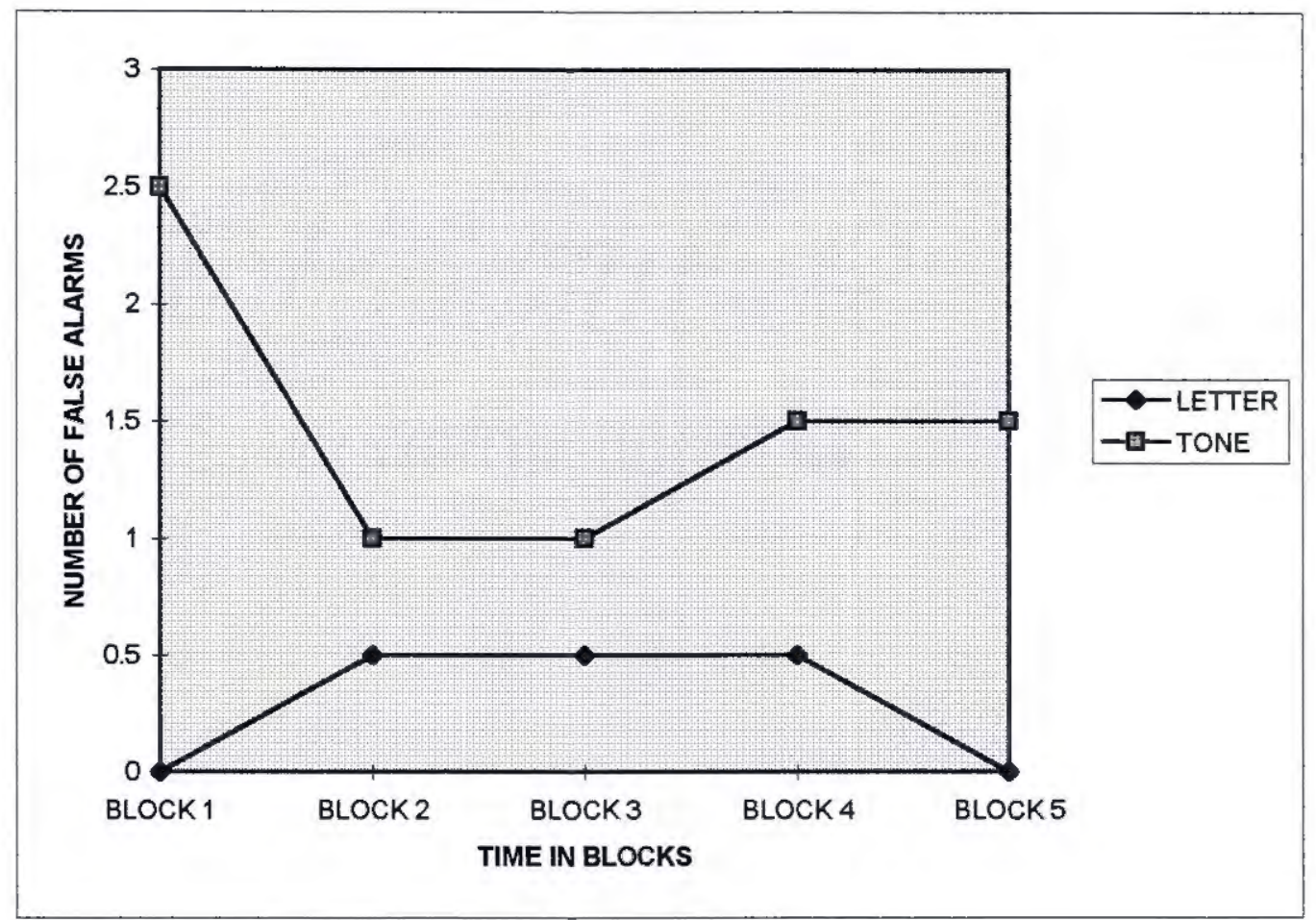

Figure 10 Mean number of false alarms by block for the letter and tone tasks. 

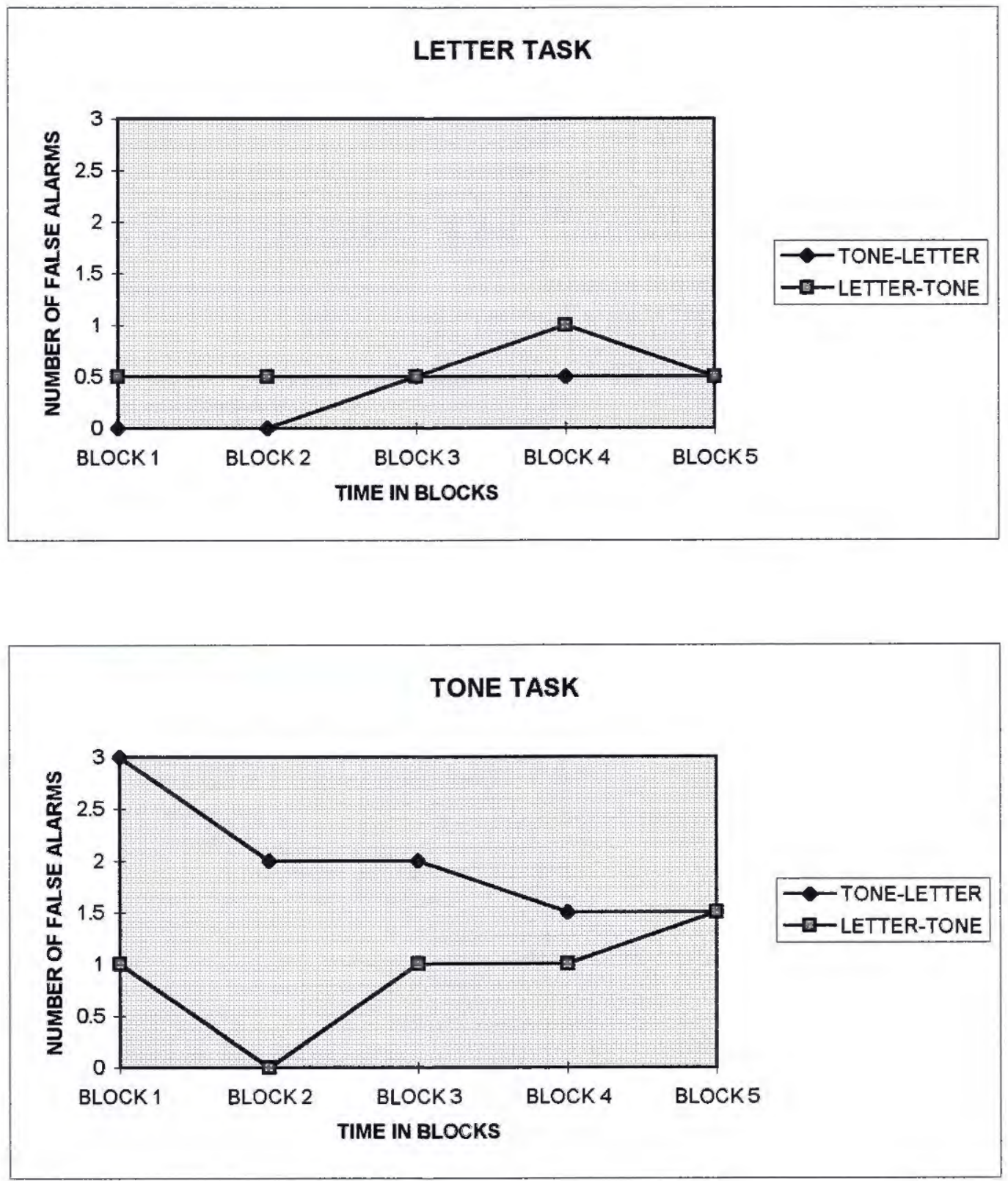

Figure 11 Mean number of false alarms by order by block for the letter and tone tasks. 

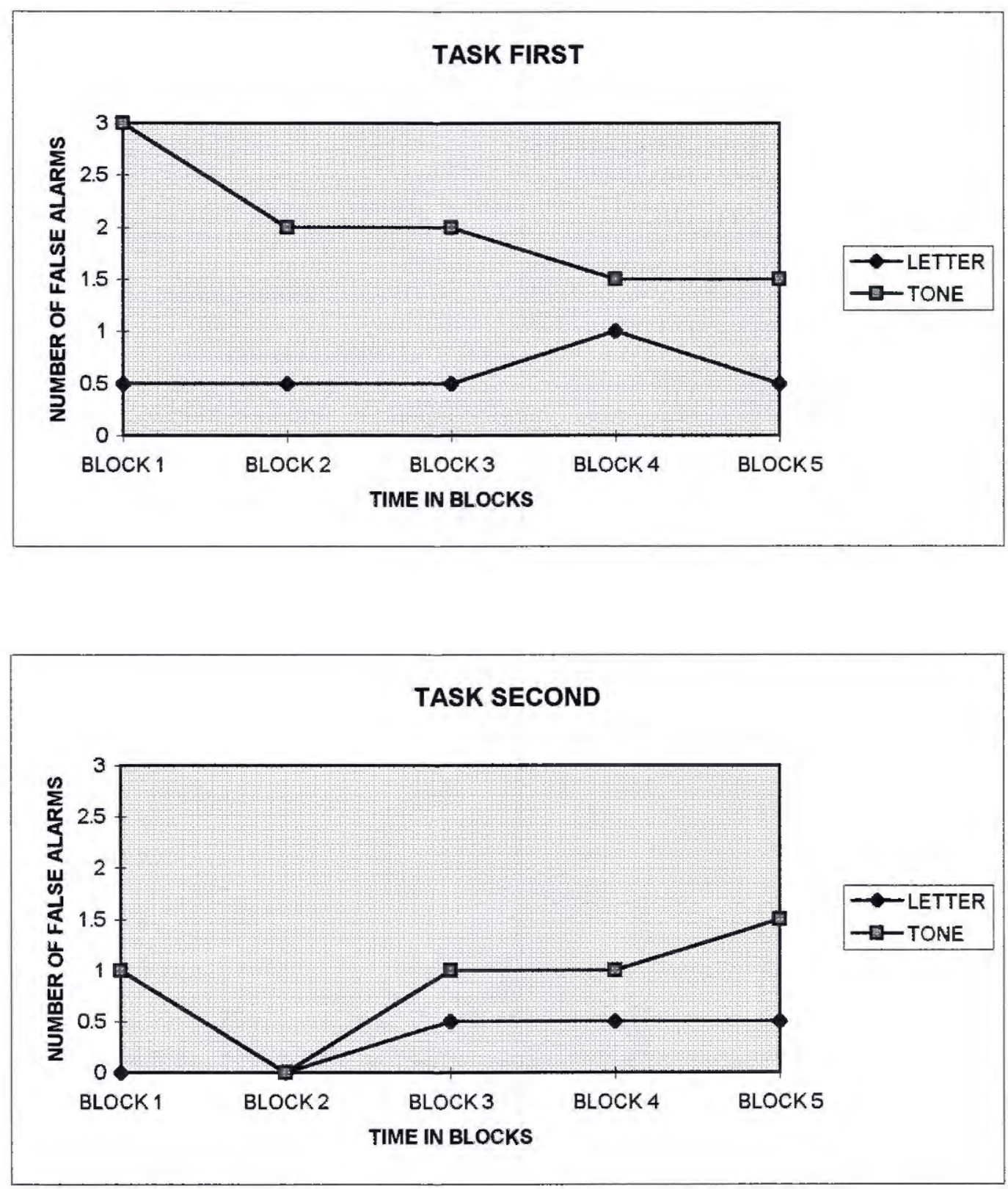

Figure 12. Mean number of false alarms by block for task when the task comes first or second in the presentation order. 
Table 6

Correlations for Accuracy by Block between the Letter and Tone Tasks

\begin{tabular}{|c|c|c|c|c|c|c|c|}
\hline & & & & Letters & & & \\
\hline & & Block 1 & Block 2 & Block 3 & Block 4 & Block 5 & Total \\
\hline & Block 1 & 0.2 & & & & & \\
\hline & Block 2 & & $0.23^{*}$ & & & & \\
\hline Tones & Block 3 & & & $0.23^{*}$ & & & \\
\hline & Block 4 & & & & $0.38 * * *$ & & \\
\hline & Block 5 & & & & & $47^{* * *}$ & \\
\hline & Total & & & & & & $0.24^{*}$ \\
\hline & & ${ }^{*} \mathrm{p} \leq .05$ & & & & & \\
\hline & & ${ }^{* *} \mathrm{p} \leq .01$ & & & & & \\
\hline & & $* * * \mathrm{p} \leq .00$ & & & & & \\
\hline
\end{tabular}

Table 7

Correlations for Adjusted Accuracy by Block between the Letter and Tone Tasks

\begin{tabular}{|c|c|c|c|c|c|c|c|}
\hline & & & & Letters & & & \\
\hline & & Block 1 & Block 2 & Block 3 & Block 4 & Block 5 & Total \\
\hline & Block 1 & $22^{*}$ & & & & & \\
\hline & Block 2 & & $24^{*}$ & & & & \\
\hline Tones & Block 3 & & & $.23^{*}$ & & & \\
\hline & Block 4 & & & & $42^{* * *}$ & & \\
\hline & Block 5 & & & & & $.48^{* * *}$ & \\
\hline & Total & & & & & & $.26^{* *}$ \\
\hline & & ${ }^{*} p \leq .05$ & & & & & \\
\hline & & ${ }^{* *} \mathrm{p} \leq .01$ & & & & & \\
\hline & & $* * * \mathrm{p} \leq .00$ & & & & & \\
\hline
\end{tabular}


Table 8

Correlations for Reaction Time by Block between the Letter and Tone Tasks

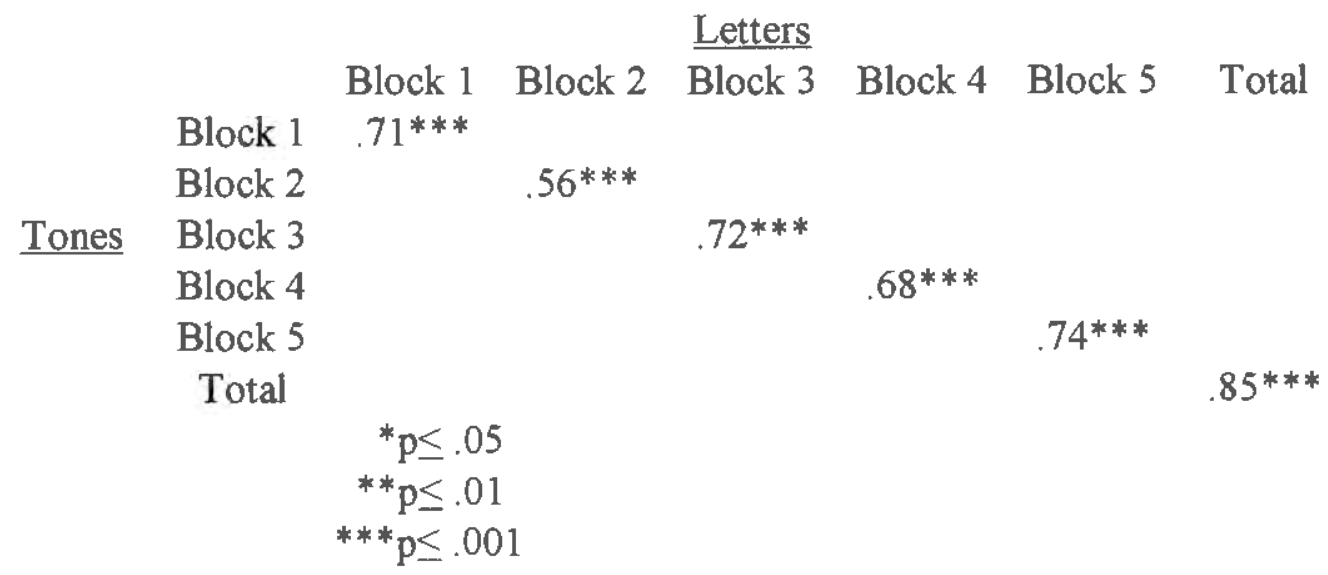

Table 9

Correlations for Error Index by Block between the Letter and Tone Tasks

\begin{tabular}{|c|c|c|c|c|c|c|c|}
\hline & & & & Letters & & & \\
\hline & & Block 1 & Block 2 & $\overline{\text { Block } 3}$ & Block 4 & Block 5 & Tota \\
\hline & Block 1 & $.22^{*}$ & & & & & \\
\hline & Block 2 & & $24^{*}$ & & & & \\
\hline Tones & Block 3 & & & $.23^{*}$ & & & \\
\hline & Block 4 & & & & $.42 * * *$ & & \\
\hline & Block 5 & & & & & $48 * * *$ & \\
\hline & Total & & & & & & $.25^{*}$ \\
\hline & & ${ }^{*} \mathrm{p} \leq$ & & & & & \\
\hline & & $* * \mathrm{p} \leq .0$ & & & & & \\
\hline & & $* * * \mathrm{p} \leq$ & & & & & \\
\hline
\end{tabular}


Table 10

Correlations for False Alarms by Block between the Letter and Tone Tasks

\begin{tabular}{|c|c|c|c|c|c|c|c|}
\hline & & & & $\underline{\text { Letters }}$ & & & \\
\hline & & Block 1 & Block 2 & Block 3 & Block 4 & Block 5 & Total \\
\hline & Block 1 & -0.18 & & & & & \\
\hline & Block 2 & & -0.12 & & & & \\
\hline Tones & Block 3 & & & -0.19 & & & \\
\hline & Block 4 & & & & 0.08 & & \\
\hline & Block 5 & & & & & 0.09 & \\
\hline & Total & & & & & & -0.05 \\
\hline & & ${ }^{*} p \leq .05$ & & & & & \\
\hline & & ${ }^{* *} \mathrm{p} \leq .01$ & & & & & \\
\hline & & $* * * \mathrm{p} \leq .00$ & & & & & \\
\hline
\end{tabular}


Table 11

Correlations within the Letter Task

$\begin{array}{cccccc} & \text { ACC } & \text { ADJ } & \text { RT } & \text { EI } & \text { FA } \\ \text { ACC } & & .78^{* * *} & (-.21)^{*} & (-.70)^{* * *} & (-.01) \\ \text { ADJ } & & & (-.06) & (-.95)^{* * *} & -0.16 \\ \text { RT } & & & & 0.05 & 0.08 \\ \text { EI } & & & & & 0.13\end{array}$

$$
\begin{aligned}
{ }^{*} \mathrm{p} & \leq .05 \\
{ }^{* *} \mathrm{p} & \leq .01 \\
* * * \mathrm{p} & \leq .001
\end{aligned}
$$

Table 12

Correlations within the Tone Task

$\begin{array}{cccccc} & \text { ACC } & \text { ADJ } & \text { RT } & \text { EI } & \text { FA } \\ \text { ACC } & & .92^{* * *} & (-.27)^{* *} & (-.92)^{* * *} & 0.03 \\ \text { ADJ } & & & (-.23)^{*} & (-1.0)^{* * *} & (-.04) \\ \text { RT } & & & & .23^{*} & 0.04 \\ \text { EI } & & & & & 0.04\end{array}$

$$
\begin{aligned}
{ }^{*} \mathrm{p} & \leq .05 \\
{ }^{* *} \mathrm{p} & \leq .01 \\
* * * \mathrm{p} & \leq .001
\end{aligned}
$$

Table 13

Correlations for Total Performance Measures Collapsed over Task

$$
\begin{array}{cccccc} 
& \text { ACC } & \text { ADJ } & \text { RT } & \text { EI } & \text { FA } \\
\text { ACC } & & .82^{* * *} & (-.23)^{* * *} & (-.75)^{* * *} & (-.08) \\
\text { ADJ } & & & (-.12) & (-.96)^{* * *} & (-.03) \\
\text { RT } & & & & 0.11 & 0.01 \\
\text { EI } & & & & & 0.03 \\
\text { FA } & & & & & \\
& * p \leq .05 & & & \\
& * * \mathrm{p} \leq .01 & & & \\
& * * * \mathrm{p} \leq .001 & & &
\end{array}
$$


Group \#

APPENDIX

Informed Consent

Subject/Patient Name

Date of Birth

(Must be 18 or older)

Institution

Location

I have been asked to take part in a research project (described below). I should feel free to ask questions of the researcher. If I have more questions later, Dr. Valentino, the person mainly responsible for the study (792-4233), will discuss them with me. I may participate in the study, or I may change my mind and withdraw at any time. I understand that I will not receive payment for my participation, nor will I be penalized in any way if I withdraw.

Researchers at the University of Rhode Island Dept. of Psychology are conducting a study to observe the relationship between attention to verbal and non-verbal tasks. I understand that I will be asked to perform a simple mental task. This task, known as a Continuous Performance Task, involves listening to letters, words or sounds and responding to some of them by pressing a button. I may be asked to fill out brief forms regarding personal information, such as my health, handedness, skills, etc.

This study will provide knowledge about how the brain processes information and where the processing may take place. This knowledge will help clinicians to do a better job recognizing abnormal attention patterns.

My privacy will be protected during the course of the study. Though the computer disk on which my records are stored may contain a label with my Social Security number, my data will always be labeled with a number code available only to Dr. Valentino. I will not be identified in any publication resulting from this study.

If I am not satisfied with the way the study is performed, I may discuss my complaints with Dr. Valentino or with the Psychology Department Chairperson, Dr. Janet Kulberg (792-2 I93), anonymously, if I choose. In addition, I may contact the office of the Vice Provost for Research, 70 Lower College Road, University of Rhode Island, Kingston, R.I., telephone: (401) 792-2635.

I have read the Consent Form. My questions have been answered. My signature on this form means that I understand the information and I agree to participate in this study.

Signature Date

Print Name

Investigator Date

Print Name 


\section{Bibliography}

Azar, B. (1995, November). Attitude affects memory, decisions, and performance Monitor, p. 27.

Damasio, A. R. (1995). Descartes Error. New York: Avon.

Davies, D. R., \& Parasuraman, R. (1982). The Psychology of Vigilance. New York: Academic Press.

Davies, D. R., \& Parasuraman, R. (1982). Vigilance and the brain. In P. Warr (Series Ed.) \& Davies, D. R. \& Parasuraman, R. (Vol. Eds.), Organizational and Occupational Psychology: Vol. 8. The Psychology of Vigilance (pp. 181-207). London: Academic Press.

Drain, M., \& Reuter-Lorenz, P. A. (1996). Vertical orienting control: Evidence for attentional bias and "neglect" in the intact brain. Journal of Experimental Psychology: General, 125 (2), 139-158.

Hallowell, E. M., \& Ratey, J. J. (1994). Driven to Distraction. New York: Pantheon.

Halperin, J. M., Sharma, V., Greenblatt, E., \& Schwartz, S. T. (1991). Assessment of the continuous performance test: Reliability and validity in a nonreferred sample. Psychological Assessment: A Journal of Consulting and Clinical Psychology, 3 (4), 603-608.

Kastner, M. P., (1994). A pilot study to develop and compare performance on a verbal visual, and an abstract visual continuous performance test. Unpublished master's thesis, University of Rhode Island, Kingston. 
Kaufman, A. S. (1990). Assessing Adolescent and Aduit Intelligence. Boston: Allyn \& Bacon.

Lang, P. J. (1995). The emotion probe: Studies of motivation and attention. American Psychologist, 50 (5), 372-385.

Lezak, M. D. (1995), Neuropsychological Assessment (3rd edition). New York: Oxford University Press.

Loeb, M., \& Alluisi, E. A. (1984). Theories of vigilance. In D. H. Holding (Series Ed.) \& J. S. Warm (Vol. Ed.), Wiley Series on Studies in Human Performance: Vol. 4. Sustained Attention in Human Performance (pp. 179-205), Chichester: John Wiley \& Sons, Ltd.

Luria, A. R. (1973). The Working Brain: An Introduction to Neuropsychology Basic Books.

McKiernan, K. A., \& Reeve, N. M., (1995). The influence of emotion on sustained attention. Unpublished manuscript. University of Rhode Island, Kingston.

Parasuraman, R. (1984). The psychobiology of sustained attention. In D. H. Holding (Series Ed.) \& J. S. Warm (Vol. Ed.), Wiley Series on Studies in Human Performance: Vol. 4. Sustained Attention in Human Performance (pp. 61-101). Chichester: John Wiley \& Sons, Ltd.

Pliszka, S. R, McCracken, J. T., Maas, J. W. (1996). Catecholamines in attention-deficit hyperactivity disorder: Current perspectives. Journal of the American Academy of Child and Adolescent Psychiatry, 35 (3), 264-272. 
Podell, K., Lovell, M., Zimmerman, M., \& Goldberg, E. (1995). The cognitive bias task and lateralized frontal lobe functions in males. Journal of Neuropsychiatry, 7 (4), 491-501.

Posner, M. I., \& Dehaene, S. (1994). Attentional networks. TINS, 17 (2), 75-79.

Prather, P., \& Kaplan, E. (in press). Attention and its disorders: Facts physiology and a theoretical framework. Discussions in Neurosciences.

Randel, D. M., Ed. (1986). The New Harvard Dictionary of Music. Cambridge, MA: Harvard University Press.

Revelle, W. (1992). Differences in personality and motivation. In A. Baddeley \& W. Weiskrantz (Eds.), Attention: Selection Awareness and Control: A Tribute to Donald Broadbent (pp. 346-373). Oxford: Clarendon Press.

Sattler, J. M. (1992). Assessment of Children: Revised and Updated Third Edition. San Diego: Sattler.

See, J. E, Howe, S. R, Warm, J. S., \& Dember, W. N. (1995). Meta-analysis of the sensitivity decrement in vigilance. Psychological Bulletin, 117 (2), 230-249.

Spreen, O., Risser, A. H., Edgell, D. (1995). Developmental Neuropsychology. New York: Oxford University Press.

Stern, R. A., Arruda, J. E., Hooper, C. R., Wolfner, G. D., \& Morey, C. E. (in press). Visual analog mood scales to measure internal mood state in neurologically impaired patients: description and initial validity evidence. Aphasiology.

Thayer, R. E. (1989). The Biopsychology of Mood and Arousal. New York: Oxford. 
Tomporowski, P. D., \& Tinsley, V. (1994). Effects of target probability and memory demands on the vigilance of adults with and without mental retardation. American Journal on Retardation, 98 (6), 688-703

Warm, J. S. (1984). An introduction to vigilance. In D. H. Holding (Series Ed.) \& J. S. Warm (Vol. Ed.), Wiley Series on Studies in Human Performance: Vol. 4. Sustained Attention in Human Performance (pp. 1-14, 323-331). Chichester: John Wiley \& Sons, Ltd.

Weyandt, L. L., Linterman, I., \& Rice, J. A. (1995). Reported prevalence of attentional difficulties in a general sample of college students. Journal of Psychopathology and Behavioral Assessment, 17 (3), 293-304.

Weyandt, L. L., Rice, J. A., Emert, E. Linterman, I., \& Mitzlaff, L. (1996). Neurological performance of a sample of adults with ADHD, developmental reading disorder, and controls. Unpublished Manuscript. Central Washington University.

Whitehead, R. (1991). Right hemisphere processing superiority during visual sustained attention. Journal of Cognitive Neuroscience, $3,329-334$. 